\title{
LA EVOLUCIÓN POLÍTICO-CONSTITUCIONAL DE LA REPÚBLICA DE COLOMBIA 1976-2005
}

\author{
The political-constitutional evolution \\ in the Republic of Colombia 1976-2005
}

\author{
Julio C. Ortiz Gutiérrez ${ }^{1}$ \\ Profesor de la Universidad Externado de Colombia \\ julio.ortiz@julioortiz.com
}

RESUM EN: El autor examina la notable y significativa evolución político-constitucional de la República de Colombia en el periodo 1976-2005, con énfasis en el estudio de las vías constitucionales empleadas para la terminación o para el llamado "Desmonte del Frente Nacional" de una parte, y, de otra, presenta, con especial atención el significado y la importancia democrática y social de la Carta Política de 1991 y de sus abundantes desarrollos, la evolución del régimen político constitucional de Colombia en la etapa que llama postconstitucional.

PA LA BRA S CLAVE: Sistema constitucional. Régimen democrático. Sistema político presidencialista. Sistema judicial. Derechos fundamentales.

ABSTRACT: The author examines the dramatic and significant political and constitutional developments in the Republic of Colombia in the period 1976-2005, with an emphasis on the study of constitutional channels used for termination or for the socalled "Dismantle the National Front" in one hand, and on the other hand shows, with special attention to the significance and importance of the social and democratic Constitution of 1991 and its many developments, the evolution of Colombia's constitutional political system in the stage that calls postconstitucional.

KEY WORDS: Constitutional system. Democratic regime. Presidential political system. Judicial system. Fundamental rights.

1 El autor es Presidente de la Sección Colombiana del Instituto Iberoamericano de Derecho Constitucional. Artículo recibido el 15 de agosto de 2008 y aprobado el 30 de octubre de 2008. 


\section{INTRODUCCIÓN}

1. De conformidad con la tradición científica del Instituto Iberoamericano de Derecho Constitucional y del Instituto de Investigaciones Jurídicas de la UNAM, en este nuevo coloquio nos ocupamos de examinar la evolución político-constitucional de las naciones y de los estados de Suramérica en el periodo que corre entre 1976 y 2005.

2. En este informe ponencia presentamos la evolución político-constitucional de la República de Colombia en este periodo de nuestra historia, con énfasis en el estudio de las vías constitucionales empleadas para el llamado "Desmonte del Frente Nacional" (1970-1978) de una parte; además, examinamos el proceso de grave descomposición de orden público de la década de los años ochentas y del bloqueo progresivo en el poder o de cierre del régimen político que concluye en la convocatoria extraconstitucional de la llamada Asamblea Nacional Constitucional o Constituyente de 1991. ${ }^{2}$

3. En este informe presentaré la notable y significativa evolución del régimen político constitucional de Colombia en la etapa que llamamos postconstitucional o de la consolidación de la democracia (1991-2005), con especial atención en el significado y en la importancia democrática e institucional de la Carta Política de 1991 y de sus abundantes desarrollos legales y jurisprudenciales. Como lo advierte Pécaut, "Este periodo estuvo sin embargo marcado por hechos tan importantes como la reunión de la Asamblea Nacional Constituyente, el cambio del modelo económico, la crisis del gobierno de Samper, el fortalecimiento de las FARC y el aumento de la influencia de las organizaciones paramilitares". ${ }^{3}$

3. Esta parte de la evolución de la historia político-constitucional de la República de Colombia, corresponde, cuando menos después de 1991, a la de mayores cambios y de más profundas y veloces transformaciones institucionales, todas ellas introducidas de modo constitucional y legal; en todo caso y después de 1991, dichas transformaciones se introducen dentro de los cauces de la continuidad democrática y constitucional. ${ }^{4}$

Durante esta última etapa del desarrollo político constitucional, también se produce la consolidación del nuevo modelo de justicia constitucional gracias al inmenso vigor de

2 Cabe advertir que en la opinión mayoritaria de los constitucionalistas colombianos el procedimiento de adopción de la nueva Carta Política de 1991 configuró una vía extraconstitucional, adoptada después de un largo proceso de bloqueo en el poder y de cierre institucional que impedía la adopción pacifica de las principales reformas que reclamaban el régimen político, electoral y territorial y el modelo económico de la Constitución de 1886 con sus reformas. Desde luego, este procedimiento se adelantó sin ruptura previa del régimen democrático, bajo la vigencia de decretos de Estado de Sitio y con el insólito aval aprobatorio de la Corte Suprema de Justicia, radical contradictora de los intentos de cambio constitucional sustancial anteriores.

3 Pecaut, Daniel (2006), Crónica de cuatro décadas de política colombiana (Bogotá, Ed. Grupo Editorial Norma, Colección Vitral).

4 De la Calle, Humberto (2004), Contra todas las apuestas. Historia íntima de la Constituyente de 1991, (Bogotá, Editorial Planeta Colombiana). 
las acciones constitucionales previstas para la protección directa, inmediata y específica de los derechos constitucionales como la acción de tutela y las acciones populares y con la presencia legítima de la Corte Constitucional, el Consejo Superior de la Judicatura y la Fiscalía General de la Nación como nuevos organismos constitucionales encargados de la impartición de justicia. Además, en este desarrollo postconstitucional encontramos los retos que han planteado al régimen político constitucional colombiano los nuevos costos fiscales de los llamados derechos constitucionales fundamentales y los de las transferencias de recursos ordinarios y de regalías a las entidades territoriales y así como los que ha generado la superación del conflicto interno con los enfrentamientos criminales entre las FARC y los grupos de las denominadas autodefensas AUC y la acción del Estado para su sometimiento e incorporación social y económica. ${ }^{5}$

Igualmente, se debe mencionar la notoria y desapacible controversia política sobre la introducción, en el 2005, de la regla inédita de la reelección inmediata del Presidente de la República, que recientemente es materia de nueva revisión y debate.

4. Así las cosas, el período que analizaremos en este informe se divide en dos etapas bien diversas y separadas por la Carta Política de 1991 llamadas:

\footnotetext{
a. Preconstitucional, para la que va desde 1976 hasta la expedición de la Carta Política de 1991, y
}

En este punto vale la pena adelantar que después de la puesta en vigencia de la Carta Política de 1991, se han producido algunas reformas en unos casos o contrarreformas en otros que han significado alteraciones parciales de las reglas del régimen político nacional como se verá más adelante; empero menciono las siguientes reformas a modo de anticipación conceptual, así entre otros: a. El establecimiento en 1997, por reforma constitucional del Congreso de la República durante el Gobierno de Ernesto Samper Pisano de la institución de la extradición de nacionales colombianos por nacimiento, con lo cual se derogó la cláusula que la prohibió en la Asamblea Nacional Constituyente (Art. 35 CP). b. La supresión por reforma constitucional en el Congreso de la República y en 1999, durante el gobierno de Andrés Pastrana Arango, de la disposición que autorizaba la expropiación sin indemnización por razones de equidad cuando fuera decretada por en el Congreso en votación cualificada (Art. 58 CP). c. Las tres modificaciones constitucionales al régimen de transferencias a las entidades territoriales de recursos fiscales corrientes y ordinarios del Estado y de los ingresos provenientes de la explotación de los recursos naturales no renovables también adoptadas en el Congreso (Arts. 346, 356, 357). d. Las cuatro reformas políticas introducidas en 1993, 2002, 2003 y 2005 que modificaron el régimen de inhabilidades e incompatibilidades, de los partidos y movimientos políticos, los periodos de los alcaldes, gobernadores, concejales y diputados, del estatuto de las elecciones y de la oposición y la organización electoral (Arts. 107, 108, 109, 111, 112, 134 y 261 de la CP). e. La modificación y la notable flexibilización, también durante el gobierno de Andrés Pastrana Arango en el 2002, de una de las condiciones para adquirir la nacionalidad por nacimiento de los nacidos en el exterior e hijos de padre o madre colombiano (Art. 96 CP). f. La reforma en el 2002 tramitada durante los gobiernos de Andrés Pastrana A rango y de Álvaro Uribe Vélez del Régimen Penal Colombiano con la introducción del Sistema Penal Acusatorio, los juicios orales y públicos y el régimen de la defensoría pública (Arts. 250, 251 CP). g. La reforma constitucional adoptada por Referendo en 2004 del artículo 122 de la Carta Política, del régimen de pérdida de derechos políticos de los servidores públicos por sanciones penales, como consecuencia de la comisión de delitos que afecten el patrimonio del Estado o de conductas que afecten el patrimonio público. h. El establecimiento en el 2004 de la reelección inmediata para el Presidente de la República (Arts. 127, 197, 204 CP). 
b. Postconstitucional, desde la entrada en vigencia de la Carta Política de 1991, hasta el 2005.

5. Se debe precisar que la anterior Constitución Política de Colombia es la de 1886 y que ésta rigió de modo continuo durante ciento seis (106) años sin perder su vigencia plena, salvo en el periodo de cinco (5) años de la dictadura militar que va de 1953 a 1958, en el que también se aplicó parcialmente.

A quella Constitución, que reemplazó a la federal, liberal y radical de 1863 y que es atribuida al pensamiento conservador, centralista y unitario de gobierno de la Regeneración de Rafael Núñez, fue objeto y materia de reformas de variada entidad ideológica y orgánica para incluirle los matices y acentos sociales y técnicos que fuese posible, pero las más desatacada son las introducidas en 1910, 1936, 1945, 1968 y 1986. También, como se verá más adelante, a aquella Constitución se le introdujeron dos reformas constitucionales en 1977 y 1979 que fueron retiradas del ordenamiento jurídico colombiano por sentencias de la Sala Plena de la Corte Suprema de Justicia a pesar de encontrarse en vigencia y con vigor pleno.

\section{EL PEQUEÑO MUNDO NUESTRO QUE SE DERRUMBÓ}

1. El nuevo texto constitucional de 1991 significó el inicio del proceso de cambio, reestructuración, actualización y democratización de las más importantes piezas del régimen político colombiano, todo lo cual había sido aplazado por varias y muy profundas causas durante casi todo el siglo XX.

Desde luego y a pesar de ser derogada por la Carta Política de 1991, en el nuevo texto constitucional de Colombia se encuentran algunos pocos de los contenidos originales de la vieja Constitución de 1886 y de sus evoluciones históricas. ${ }^{6}$

Con este cambio en 1991 se introdujeron nuevas instituciones en materia de los derechos de las personas y de los instrumentos y procedimientos de su protección, se reconocieron nuevos y múltiples actores legítimos en el proceso social y político na-

6 Las pocas instituciones de la Constitución de 1886 que se mantienen sustancialmente idénticas en la de 1991, son, entre otras: a. La existencia de la doble jurisdicción como la ordinaria, con la Corte Suprema de Justicia, los tribunales superiores de distrito judicial y los juzgados civiles, de una parte, y la contencioso administrativa con el Consejo de Estado y los tribunales contencioso administrativos, de otra; b. La vieja noción de gobierno sin gabinete. c. Con una breve modificación aditiva, se mantiene la estructura central de la administración en la Rama Ejecutiva con los ministerios, departamentos administrativos, establecimientos públicos, empresas industriales y comerciales del Estado, sociedades de economía mixta y corporaciones autónomas regionales; d. Las viejas e históricas características y atributos generales del presidente colombiano; e. La pesada institución de la Procuraduría General de la Nación, f. La soberanía de la Nación y de la Ley en materia de impuestos, g. La propiedad estatal del subsuelo y de los recursos naturales no renovables; h. La edad de 18 años para adquirir la ciudadanía, e i. la elección popular de los alcaldes. 
cional, así como nuevas reglas en materia de la estructura de los órganos y de los controles del poder, de la democracia y de la organización territorial.

A demás, la nueva Constitución significó la introducción de un nuevo régimen económico y de un nuevo modelo orgánico del Estado.

2. Como antecedente inmediato de este informe y ponencia sobre la evolución político constitucional de la republica de Colombia de 1976 a 2005, advertimos que en marzo de 1976 el profesor colombiano Carlos Restrepo Piedrahita elaboró y presentó en el Coloquio de Oaxtepec -M éxico- y bajo el mismo auspicio del Instituto Iberoamericano de Derecho Constitucional y del Instituto de Investigaciones Jurídicas de la UNAM que ahora nos convoca, el informe sobre la evolución político constitucional de la República de Colombia correspondiente al periodo comprendido entre los años 1950 y 1975.

Dicho trabajo fue posteriormente publicado con algunas adiciones en la Universidad Externado de Colombia, con prólogo del Presidente de la República Alfonso López Michelsen; ${ }^{7}$ allí se sostiene que en el periodo que se examinó en el citado coloquio de Oaxtepec, no hubo, salvo algunos retoques, ninguna evolución sustancial, pues fue evidente el predominio en la República de Colombia de las ideas y del pensamiento político del presidencialismo dirigido y restringido, con gobiernos bipartidistas y hegemónicos, denominados consociacionales, ${ }^{8}$ previstos para que funcionaran bajo las reglas aplicables para estados de excepción (Estado de Sitio-Emergencia Económica) y con la generosa entrega gratuita y permanente de Facultades Extraordinarias o de delegaciones legislativas para el poder ejecutivo.

4. La otra expresión dominante de ese período, según Restrepo, fue el establecimiento inicial de la excluyente paridad política liberal-conservadora que llegó a comprender de modo milimétrico a la Rama Judicial y la rígida alternación de los dos partidos en el acceso a la presidencia de la república en su versión inicial y, luego, la representación y la participación adecuada y equitativa del segundo partido que seguía al del presidente a la hora de designar ministros e integrar el mal llamado Consejo de Ministros o Gabinete Ministerial, lo cual significó la prórroga del Frente Nacional por ocho años más. ${ }^{9}$

5. En Colombia tuvimos un muy largo periodo de más de cuarenta (40) años de predominio del Estado de Sitio y de la Emergencia Económica como instrumentos

Restrepo Piedrahita, Carlos (1976), 25 Años de Evolución Político-Constitucional 1950-1975 (Bogotá, Editorial Universidad Externado de Colombia).

8 HaRTLYN, Jonathan (1998), "El presidencialismo y la Política Colombiana", en Las crisis del Presidencialismo, volumen 2. El caso latinoamericano (M adrid, Ed. Alianza Universidad).

9 En este sentido es abundante la bibliografía que puede ser consultada sobre la materia y que aparece mencionada en el acápite correspondiente de esta ponencia; especialmente se tiene en cuenta la investigación de Jonathan Hartlyn de 1993 que aparece citada más arriba: La política del Régimen de Coalición, la Experiencia del Frente Nacional en Colombia. 
extraordinarios autorizados directamente por la Constitución para que el presidente gobernara por medio de Decretos Legislativos de una parte, y de otra, por virtud de la Ilamada legislación extraordinaria habilitada por el Congreso de la República por medio de Leyes de Facultades Extraordinarias para que el presidente gobierne y legisle por Decreto Ley. ${ }^{10}$

Se trató de las peores y más censuradas y defectuosas características del precario modelo constitucional y del régimen político colombiano que se desarrolló desde la situación de pillaje y barbarie de 1948, y que se extendió con mucha intensidad durante la primera etapa del período constitucional que examinamos en este informe, es decir, desde 1975 hasta 1991. A pesar de aparecer como instituciones excepcionales y extraordinarias, lo cierto es que aquellos institutos constitucionales en Colombia funcionaron como recursos instrumentales e institucionales de carácter permanente hasta dominar por completo el escaso escenario de la gobernabilidad nacional. Aquí se debe recordar la existencia de otras instituciones políticas nacionales de desastrosas consecuencias paral la democracia y para el régimen político constitucional, como son los llamados auxilios parlamentarios y el régimen de los suplentes de los congresistas. ${ }^{11}$

En varias oportunidades hemos sostenido que se trató de una serie de instrumentos constitucionales de naturaleza excepcional y extraordinaria, puestos en manos del jefe del poder ejecutivo, incorporados y adaptados paulatinamente a la Constitución de 1886 para garantizar el poco espacio de poderes ordinarios concedidos al Presidente de la República.

Como se conoce en Colombia, los auxilios parlamentarios consistían en la capacidad de introducir en la ley anual de presupuesto partidas que los mismos congresistas podían asignar y distribuir directamente entre sus electores para proyectos en sus regiones; además, los llamados carruseles de suplentes eran el resultado de los acuerdos con los varios jefes regionales denominados caciques que podían ingresar paulatina y progresivamente a ocupar curules o escaños durante las legislaturas para obtener preciosas pensiones personales y distribuir favores regionales o familiares.

6. Es preciso advertir que esta configuración dominante se extiende hasta la expedición de la Carta Política de 1991, a partir de la cual las nuevas reglas de limitación y los controles de constitucionalidad en la Corte Constitucional de los regímenes de excepción y de facultades extraordinarias, han hecho casi imposible su aplicación en

10 Ver sobre esta materia a ReSTREPo PIEDRAHITA, Carlos (1973), Las facultades Extraordinarios, Pequeña Historia de una Transfiguración (Bogotá, Ed. Universidad Externado de Colombia).

11 La Reforma constitucional de 1968 es otro acuerdo bipartidista estructural, por el que en la versión final se intentó racionalizar la naturaleza y los alcances de la institución del Estado de Sitio; con ella se creó una institución separada llamada de emergencia económica y social y se estableció el mecanismo de control constitucional automático y forzoso ante la Sala Plena de la Corte Suprema de Justicia, obviamente bipartidista y paritaria con la participación de la llamada Sala Constitucional de aquella Corporación Judicial. Cabe destacar que en esta reforma se introdujo el régimen de los auxilios parlamentarios y los llamados carruseles de suplentes. 
este nuevo período en el caso de los varios regímenes de facultades extraordinarias y de estados de excepción. ${ }^{12}$

Los auxilios y los carruseles de suplentes se han tratado de revivir por varias vías y reformas al texto de la Carta Política de 1991.

7. Además, después de 1958, el régimen presidencial colombiano resultó condicionado de manera radical por el marcado y excluyente bipartidismo de fracciones que permitía al Presidente de la República gobernar con formas de participación burocrática como la de la absoluta paridad excluyente liberal-conservadora y, posteriormente, para introducir una especie de transición, con la fórmula de la representación adecuada y equitativa del partido que le seguía en votos al del presidente y con la de la colaboración personal y técnica de los ministros. Se reitera, se trató de la prolongación del Frente Nacional por ocho (8) años ordenada por la reforma constitucional de 1968.

De otra parte, no existieron, durante muchos años, ni la noción de gobierno de partido, ni de partido de gobierno, ni la de partidos de oposición, salvo presencia breve del MRL, la casi victoriosa de la ANAPO y la trágica incursión electoral y política de la Unión Nacional de Oposición UNO.

7. En este sentido, y como lo desarrollaré más adelante, Restrepo Piedrahita (1998) también sostiene que entre 1975 y 1991 en Colombia se produjeron lo que se denominaron tres golpes de Estado en frío o tres golpes en y desde el Estado, ejecutados por el poder judicial desde la Corte Suprema de Justicia y el Consejo de Estado, que declararon inconstitucionales los tres intentos de introducir reglas para el cambio político y social con las reformas constitucionales de 1977 y 1979 y el llamado acuerdo de la Casa de Nariño. ${ }^{13}$

Como veremos más adelante, en aquella primera parte de este estudio se trata de la etapa en la que tuvo plena vigencia del modelo consocional ${ }^{14}$ liberal conservadorconservador liberal que impuso fuertes limitaciones a la democracia y que configura una forma de evidente presidencialismo dirigido y limitado. ${ }^{15}$

12 A hora, bajo la Carta Política de 1991 se trata de las instituciones de los estados de excepción denominados conmoción interior y las emergencias, cuyas varias clases son las de emergencia económica, social, ecológica o de calamidad pública. Arts. 213, 214 y 215 C.P. Estas nuevas instituciones están sometidas a limitaciones especiales como las que establece el derecho internacional de los derechos humanos, el llamado bloque de constitucionalidad, la ley estatutaria de estados de excepción y los controles automáticos de constitucionalidad en la Corte Constitucional y el control político del Congreso de la República.

13 Restrepo Piedrahita, Carlos (1998), Evolución Constitucional en el Siglo XX, en memorias del Congreso Iberoamericano de Derecho Constitucional, Tomo I (Bogotá, Ed. Universidad Externado de Colombia).

14 HaRTLYN, Jonathan (1998). El presidencialismo y la Política Colombiana, en Las crisis del Presidencialismo, Volumen 2. El caso latinoamericano (Madrid, Ed. Alianza Universidad).

15 CARPIzo, Jorge (2007), Concepto de democracia y sistema de gobierno en A merica Latina (M éxico DF, Ed. Universidad Nacional Autónoma de México, Instituto de Investigaciones Jurídicas). 
La singular ausencia de rupturas de los gobiernos civiles y de continuada estabilidad constitucional y económica, también se acompaña de una especie de tendencia sostenida de crecimiento relativo y de paulatino y desordenado desarrollo social, así como de la transformación de los modelos de crecimiento tradicionales por el paso del predominio del régimen agrario al de la urbanización y del crecimiento de las ciudades. A quella característica marca una gran diferencia de lo que se ha afirmado de los periodos políticos y constitucionales precedentes y de toda la historia republicana de nuestro país.

No sobra destacar la muy significativa e impactante tendencia de aumento del poder del narcotráfico y de los narcotraficantes colombianos en la economía y en la política nacional y la relativa estabilidad y continuidad del modelo económico colombiano. López Restrepo sostiene que "...Colombia tiene condiciones que han favorecido la expansión de actividades ilegales, incluidos el narcotráfico y la violencia política. A mbos fenómenos, a su vez, le permiten al otro mantenerse y crecer: el narcotráfico genera recursos que financian a los actores armados ilegales y los actores armados ilegales debilitan al Estado y así facilitan el narcotráfico". ${ }^{16}$

Durante este periodo se produjo la articulación vigorosa de varios cárteles y alianzas armadas de narcotraficantes capaces de desafiar el poder y la autoridad del Estado y de provocar, con las bandas y grupos de guerrilleros, verdaderas colonizaciones armadas de vastos territorios del país, hasta el punto de provocar conceptualizaciones complejas del régimen político como las de una especie de Estado Fallido y las de unas especies de Anomia Jurídica.

Esta configuración de la sociedad colombiana basada en la fuerza inmensa de los delincuentes dedicados al tráfico de drogas ilícitas y de armas y al contrabando de toda clase de mercancías, comprende, además la capacidad de desafiar a las fuerzas militares y de policía y de producir muy fuertes ataques terroristas y crímenes selectivos o indiscriminados, como los conocidos magnicidios y los asaltos como el del palacio de justicia de la República.

8. Como lo advertimos más arriba, en el anterior modelo de régimen político colombiano, configurado durante más de cien (100) años, supuestamente superado con la nueva Carta Política de 1991, la mayor parte del soporte político del Presidente de la República y la fuerza de la integración del llamado gabinete del gobierno nacional, se obtenía, en periodos de paz pública o de suspensión de los enfrentamientos entre los dos partidos, con los compromisos de los expresidentes y de sus facciones sólidamente constituidas y, casi siempre, los ministros y directores de departamento administrativo representaban o a amigos y colaboradores personales del Presidente en ejercicio, 0 a amigos y colaboradores de los expresidentes o de los hijos prestantes de éstos.

16 López Restrepo, Andrés (2006), Narcotráfico, ilegalidad y conflicto en Colombia, en Nuestra Guerra sin Nombre (Bogotá, Ed. Grupo Editorial Norma Colección Vitral, Universidad Nacional de Colombia, Instituto de Estudios Políticos y Relaciones Internacionales IEPRI). 
9. Obsérvese que en nuestro régimen político constitucional tampoco ha existido la noción orgánica de gobierno en el sentido parlamentario o semipresidencial, más bien el conjunto de los ministros o secretarios del poder ejecutivo funcionaba como la reunión de los voceros delegados de los expresidentes que entraban al acuerdo burocrático para la gobernabilidad.

Además, el viejo modelo del presidencialismo colombiano fue denominado por la doctrina constitucional como un régimen de Presidencialismo dirigido ya que "... conserva las características del (presidencialismo) puro, pero con limitaciones, ya sean impuestas o voluntarias a la libertad y a la participación de las fuerzas políticas en el gobierno del país". ${ }^{17}$

10. La democracia como régimen político en Colombia fue hasta la expedición de la Carta Política de 1991, notable expresión de un modelo consocionalista y limitado; al respecto se advierte que el consociacionalismo por su naturaleza impone ciertos límites a las prácticas de la democracia mayoritaria y que en el régimen político colombiano del Frente Nacional, aun después de su desmonte constitucional, llevó a la existencia de severas restricciones adicionales impuestas sobre la democracia política del país, hasta el año de 1986. En el Gobierno de Virgilio Barco Vargas se planteó con muchas dificultades y obstáculos el nuevo modelo del régimen de gobierno de partido y de partidos de oposición en cuya formulación tuvieron importante participación los profesores Mario Latorre Rueda y Fernando Cepeda Ulloa.

11. Además, como lo reconocen los más importantes especialistas, esta etapa de la vida constitucional de Colombia en el conjunto de países vecinos y de la región, hace parte del largo periodo de continuidad civil pactada de más de cincuenta años que se remonta al acuerdo civil bipartidista para superar la dictadura del General Rojas Pinilla (1953-1957) y de una suerte de notable estabilidad macroeconómica y de la ausencia de rupturas autoritarias, populistas o militares. ${ }^{18}$

12. El aseguramiento de aquella continuidad es atribuible originariamente al modelo cuasidemocrático y consocional bipartidista, de una parte, como producto de los pactos de 1957 y 1958 para superar las violencias precedentes y de otra parte del reiterado uso

17 Cfr. CARPIZO, Jorge (2007), Concepto de democracia y sistema de gobierno en América Latina (M éxico DF, Ed. Universidad Autónoma de M éxico, Instituto de Investigaciones Jurídicas).

18 Dávila Ladrón de Guevara, Andrés (2002), Democracia Pactada, El Frente Nacional y el Proceso constituyente de 1991 (Bogotá, Ed. A lfaomega Grupo Editor, Universidad de los Andes, CESO Departamento de Ciencia Política); allí se advierte en un útil resumen que los principales pactos que dan lugar a la fórmula del Frente Nacional son el Acuerdo de Benidorm firmado en julio de 1956, el Pacto de Marzo firmado en marzo de 1957, el programa de gobierno de la Junta Militar y de integración del "Gabinete Bipartidista", el Acuerdo de Sitges, firmado en julio de 1957, la redacción bipartidista y militar de los textos para presentar al mal llamado Plebiscito programado para el 10 de diciembre de 1957, el Pacto de San Carlos sobre candidaturas y el Acto Legislativo $\mathrm{N}^{\circ} 1$ de 1959 o de reforma constitucional sobre la obligatoriedad de alternación bipartidista propuesta por Laureano Gómez el 7 de abril de 1958 y adoptado por el primer Congreso de la República posterior a la interrupción militar. 
de las herramientas constitucionales más funcionales y efectivas como son la plena paridad política liberal conservadora en todos los órganos del poder público, la alternación presidencial bipartidista durante más de 16 años y las vigorosas facultades extraordinarias que permitían las instituciones del Estado de Sitio, la Emergencia Económica y las leyes de habilitación legislativa extraordinaria al poder ejecutivo.

Desde luego, todo esto incluyó el acuerdo bipartidista para transformar a la Corte Suprema de Justicia y al Consejo de Estado en los guardianes supremos del orden constitucional y legal y para cautelar de modo férreo las desviaciones presidencialistas del régimen.

\section{LOS GOBIERNOS DE CONSENSOS}

1. La noción de gobierno en el régimen político constitucional de Colombia ha sido esencialmente funcional y a ella nunca se la ha dado un alcance orgánico estructural, salvo en materia de la firma de los decretos de Estado de Sitio o de Emergencia Económica y Social que establecen los artículos 121 y 122 de la Constitución de 1886 reformada especialmente en 1968.

A demás, en el periodo que examinamos no se conoció una renuncia o una tensión en estas materias entre los miembros del llamado gabinete ministerial. También, buena parte de los expresidentes del anterior periodo constitucional, salvo Guillermo León Valencia M uñoz, a quien se le frustró la aspiración de ser el primer presidente del Frente Nacional, hicieron parte de gobiernos precedentes en su condición de ministros.

Durante todos los gobiernos de llamado Frente Nacional, el bloqueo bipartidista y paritario supuso la participación igualitaria de representantes de los directorios de los dos partidos políticos nacionales que se organizaban alrededor de los expresidentes llamados jefes naturales de los partidos.

2. Para el llamado "Desmonte del Frente Nacional", es decir desde el gobierno de Alfonso López hasta el gobierno de Julio César Turbay Ayala (1978-1982) se aplicó la formula transitoria de lo que se llamó la participación adecuada y equitativa del segundo partido que le siga en votos al del presidente elegido, como quiera que el régimen presidencial colombiano se había visto condicionado de manera radical por el marcado bipartidismo de fracciones que permitía al Jefe de Estado gobernar con estas formas "cuasidemocráticas" de participación burocrática. Igual práctica aplicó Belisario Betancourt Cuartas (1982-1986) para la integración de su gobierno y para el nombramiento de sus ministros.

3. La participación de los partidos tradicionales en toda la administración pública de la Rama Ejecutiva fue paritaria hasta 1974; además, el régimen de representación de los partidos en el Congreso de la República mantuvo la regla de la paridad absoluta hasta 1978. 
En la rama judicial dicha regla se mantuvo hasta 1991 y en las llamadas altas cortes aún hoy (2008) se mantiene un insólito sentimiento inconstitucional de bipartidismo excluyente. ${ }^{19}$

4. La elección presidencial durante los cuatro periodos del Frente Nacional (19581974) se realizaba en una sola vuelta y por mayoría simple; empero, en la práctica los debates electorales fueron ampliamente resueltos a favor del candidato oficial del partido al que le correspondía el turno de acceder a la presidencia por la alternación, pues no se admitía competencia de ningún otro partido y si se producían divisiones internas, éstas quedaban disueltas con la inscripción del candidato oficial de aquel.

El llamado Movimiento Revolucionario Liberal $(M R L)$ inscribió “irregularmente" al candidato Alfonso López Michelsen para las elecciones presidenciales en el turno conservador (1962-1966) y obtuvo más de seiscientos mil votos en el escrutinio provisional. ${ }^{20}$

5. En la elección para el periodo presidencial liberal (1966-1970) sólo se inscribieron Carlos Lleras Restrepo como candidato de unidad liberal, vencedor indiscutido con el $71 \%$ de los votos y José Jaramillo Giraldo como liberal disidente anapista.

6. Luego, en 1970 y para el último turno de la alternación bipartidista que correspondía a los miembros del Partido Conservador (1970-1974), el ex general Gustavo Rojas Pinilla se inscribió como candidato conservador por el partido Alianza Nacional Popular ANAPO, hasta el punto de casi derrotar a M isael Pastrana Borrero candidato oficial del conservativo y de la alianza bipartidista. ${ }^{21}$

7. Para la elección presidencial del primer periodo de gobierno del llamado Desmonte del Frente Nacional (1974-1978), se presentaron Alfonso López Michelsen, Álvaro Gómez Hurtado y María Eugenia Rojas de Moreno, tres hijos muy destacados de importantes expresidentes; también se presentó Hernando Echeverry M ejía como candidato de la Unión Nacional de Oposición UNO y resultó elegido Alfonso López Michelsen bajo el eslogan del Ilamado Mandato Claro. ${ }^{22}$

19 Como vimos, los gobiernos de este periodo son los de Alberto Lleras Camargo (1958-1962); Guillermo León Valencia M uñoz (1962-1966); Carlos Lleras Restrepo (1966-1970) y M isael Pastrana Borrero (19701974).

20 Fueron candidatos inscritos como conservadores en esa oportunidad, además de Guillermo León Valencia Muñoz elegido presidente, el exministro Jorge Leyva y el exgeneral Gustavo Rojas Pinilla. La inscripción de López generó una muy interesante polémica de orden constitucional no resuelta de modo definitivo en esa oportunidad.

21 También se inscribieron como conservadores Belisario Betancourt y Evaristo Sourdis. Esta elección marca uno de los hitos de la historia nacional y el llamado Movimiento 19 de abril (M 19) lo reclama como antecedente que justifica su alzamiento armado y su estructuración militar clandestina. Se puede consultar el texto de Noriega, Carlos Augusto (1998), Fraude en la elección de Pastrana Borrero (Bogotá, Ed. Oveja Negra).

22 Al respecto se puede consultar las siguientes publicaciones recientemente conocidas: RANDALL, Stephen J. (2007), Alfonso López Michelsen, su vida su época. (Bogotá, Ed. Villegas Editores) y M AYoRGA 
En este periodo comienza con una situación económica favorable, nutrida principalmente por los abundantes recursos fiscales que se obtienen por la bonanza cafetera y por la llamada bonanza de exportaciones variadas como el tráfico de marihuana y por el contrabando de varias clases de elementos clandestinos que ya anunciaban la introducción del narcotráfico y de los nuevos tipos de delitos transnacionales en materia de activos y de recursos financieros.

El Gobierno de Alfonso López debe afrontar estas dos circunstancias y se propone el cambio de buena parte de las estructuras constitucionales con la reforma de la Constitución para convocar a una Pequeña A samblea Constituyente que la Corte Suprema de Justicia declara contraria a los fundamentos constitucionales sustanciales del régimen político.

8. Para el siguiente periodo presidencial (1978-1982) se presentaron el elegido presidente Julio César Turbay A yala, liberal; Belisario Betancourt, conservador y el exgeneral Álvaro Valencia Tovar. También participaron en esa elección los candidatos de las izquierdas Julio César Pernía, Jaime Piedrahita Cardona y Socorro Ramírez.

Los gobierno de Alfonso López y Julio César Turbay, también se aplica la formula de la mayoría simple, y se repite la presencia de los candidatos presidenciales de la ANAPO y de la UNO sin amenazar la virtual elección de los candidatos de los dos partidos tradicionales.

Óscar Alarcón Núñez observa en una breve crónica del Frente Nacional que la historia de aquel modelo se caracteriza por una larga serie de paradojas poco examinadas por los especialistas en la historia de derecho constitucional colombiano. ${ }^{23}$

García, Fernando (2008), Alfonso López Michelsen, El retrato del intelectual (Bogotá, Ed. Universidad del Rosario, Facultad de Jurisprudencia).

23 Alarcón Núñez observa sobre las paradojas de la historia del Frente Nacional que "Su inspirador fue el ex presidente Alfonso López Pumarejo y uno de los primeros que lo combatió fue su hijo Alfonso López Michelsen, para lo cual creó el M RL. Luchó en contra de ese monopolio bipartidista y como jefe de su movimiento participó en su desmonte en el cuatrienio de Carlos Lleras Restrepo, durante el trámite de la reforma constitucional de 1968. Después le tocó realizarlo cuando fue elegido como el primer presidente, luego de 16 años de responsabilidad compartida.

Laureano Gómez suscribió los acuerdos del Frente Nacional a nombre del conservatismo, pero su grupo político fue minoría, tanto que durante los 16 años no pudo lograr la Presidencia. Solo en 1958 el laureanismo fue mayoría y en cambio, a partir de 1960, el ospinismo logró siempre las votaciones superiores de su partido.

Se diseñó el Frente Nacional para combatir la dictadura de Rojas Pinilla, y en el último período de los cuatro pactados el mismo general estuvo a punto de salir elegido presidente en los controvertidos comicios de 1970. La Anapo, considerado como grupo independiente, obtuvo en promedio 17,72 por ciento de la votación, superado ampliamente en 1970 cuando logró 38,68 de la votación total.

Y también el Frente Nacional se adoptó para buscar la paz, pero la exclusividad burocrática no sólo en el gobierno sino en todo el estado, creó el caldo de cultivo para que los sectores independientes, que no eran ni liberales ni conservadores, tuvieran que ir a la guerrilla para expresarse. Fue así que en sus dieciséis años de régimen nacieron las FARC, el ELN, el M-19 y otros grupos subversivos. También tuvo 
Como se observa, Alfonso López fundó el importante movimiento liberal de disidencia de izquierda llamado MRL e ingresó al gobierno de Carlos Lleras Restrepo (1966-1970) en su condición de gobernador nombrado del departamento del Cesar y luego al "gabinete" como ministro de relaciones exteriores. También, los amigos del General Gustavo Rojas Pinilla fundaron lo que se llamó la Alianza Nacional Popular $A N A P O$, y varios de ellos llegaron a ser elegidos como conservadores al Congreso Nacional y controlaron muchas asambleas departamentales y concejos municipales, y por ello participaron en varios gobiernos locales y departamentales.

9. Los grupos de izquierda reunidos en torno del Partido Comunista Colombiano $P C C$, el Movimiento Obrero Independiente y Revolucionario MOIR, y los varios grupos socialistas formaron la Unión Nacional de Oposición UNO y luego la llamada Unión Patriótica que comenzó a participar en elecciones directamente desde 1974 con muy dolorosas consecuencias como veremos más adelante para los militantes del Partido Comunista Colombiano y para varios de sus simpatizantes, acusados por los grupos paramilitares y otras fuerzas que llamados de modo eufemístico, fuerzas oscuras del régimen, de integrar las filas de las $F A R C .{ }^{24}$ Varias de sus acciones criminales ya han sido objeto de sanción penal nacional y otra buena parte de ellas han sido materia de condena en la jurisdicción internacional de los derechos humanos.

10. El gobierno de Virgilio Barco Vargas en 1986 intentó romperlo y ofreció a los electores el binomio partido de gobierno y partidos de oposición. Empero, sus intentos sucumbieron cuando fracasó en el Congreso de la República el proyecto de reforma constitucional; éste se revivió con el Acuerdo de la Casa de Nariño, también castigado de modo inmediato y abrupto con una insólita decisión de suspensión provisional dictada por el Consejo de Estado en funciones de juez contencioso administrativo. ${ }^{25}$

11. Además, después del Frente Nacional el régimen de partidos políticos colombianos y el régimen electoral permanecieron sometidos al rígido esquema de la representación proporcional arbitrado por la organización electoral con el empleo del método del cuociente electoral originario de la reforma constitucional de 1910; aquel régimen siempre fue condicionado por un alto grado de fraccionamientos locales y nacionales, lo cual propició la reproducción de una modalidad atípica de bipartidismo de clientelas y de tribus locales y regionales, incluida la administración de justicia.

Las maquinarias de los partidos en el Congreso funcionaron en los periodos de convergencia bipartidista, principalmente durante el Frente Nacional, tolerando la pro-

el Frente Nacional la intención de consolidar el bipartidismo, y resultó ser su tumba". A LARCón Núñez, Óscar (2006), “1957-1974 El Frente Nacional, en Credencial Historia”, edición 201, septiembre, Revista Credencial, Bogotá.

24 Este tema puede ser consultado en textos como el de DudLey, Steven (2008), Armas y urnas, Historia de un genocidio político (Bogotá, Editorial Planeta.); además, PeCAUt, Daniel (2006), Crónica de cuatro décadas de política colombiana (Bogotá, Ed. Grupo Editorial Norma, Colección Vitral).

25 Barco Vargas, Virgilio, Del Plebiscito a la A samblea Constitucional. Informe del Presidente de la República al Congreso Nacional, Tomo VIII, volúmenes I y II (Bogotá, Ed. Imprenta Nacional). 
longación interminable o ilimitada del Estado de Sitio y el ejercicio recurrente de una de las más dañinas formas de las facultades legislativas extraordinarias del Presidente de la República; además, avalaron la mayor parte de las leyes de traslado generoso de facultades legislativas al Presidente de la República en otra modalidad transfigurada de competencias legislativas extraordinarias concedidas por el Congreso de la República al Presidente.

12. Las listas de aspirantes al Congreso durante el Frente Nacional eran elaboradas por los expresidentes con el empleo de lo que se llamó "listas del bolígrafo", es decir confeccionadas directamente por los llamados jefes naturales de los partidos, los expresidentes en ejercicio.

La reelección indefinida de Senadores y Representantes a la Cámara generó un sistema político dominado por experimentados caciques o jefes de tribu regional que controlaron la sucesión y transformaron la política regional o local en asuntos patrimoniales y de herencia familiar.

Ese esquema los hizo propietarios de los destinos, del futuro y del trabajo de las personas, pues los viejos caciques eran los puntos de contacto con las direcciones de las fracciones de los dos partidos nacionales y fungían de instrumentos seudoinstitucionales de articulación de los poderes centrales con la periferia territorial y política.

13. El ejercicio de la gobernabilidad nacional supuso la concurrencia de los mencionados componentes democráticos del bipartidismo fraccionado y controlado por los expresidentes o por sus casas, con el férreo manejo de la burocracia nacional central y descentralizada por el presidente en ejercicio. Su distribución siempre fue generosa entre las casas de los expresidentes y en la de los senadores y representantes, así como entre los caciques locales y regionales.

En el esquema democracia-burocracia-gobernabilidad, también aparecen las recompensas nutridas con el frondoso cuerpo diplomático controlado directamente por el Presidente de la República y la distribución o asignación clientelista y patrimonialista de las notarías, fuente de enriquecimiento personal y de financiación de las campañas políticas.

En no pocos casos en extremo penosos, las notarías también servían de soporte de la economía de los senadores y representantes que podían obtener para sus recomendados la asignación de una de estas preseas; ellas eran uno de los fondos contra los que se podía girar en el sistema político colombiano para obtener la preciada gobernabilidad.

Dentro del régimen político Colombiano también se comprometían los cargos del llamado ministerio público en las regiones, pues el presidente era quien hasta 1991 nombraba a los "fiscales" departamentales y regionales. La noción tradicional e histórica del Ministerio Público en Colombia no corresponde a la de ministerio público 
penal; los anteriores fiscales de la Procuraduría General de la Nación sólo son agentes de control disciplinario y representantes de los intereses de la nación.

Otro de los focos de necrosis del sistema político lo constituían los fortines burocráticos y la fuente de corrupción que existía en las Ilamadas contralorías departamentales y en la Contraloría General de la República, pues el régimen les permitía coadministrar o cogobernar y disponer de más de treinta mil empleados en todo el territorio.

14. Buena parte del control sobre la propiedad y la orientación de los medios de comunicación como la prensa escrita, la radio y la televisión, fue ejercido por representantes de los dos partidos tradicionales y siempre estuvieron asignados a sus voceros notables, en lo que al Estado correspondía; ellos fueron dominad os por las casas políticas de los expresidentes y por las grandes facciones de los dos partidos tradicionales, también controladas por los expresidentes o sus "delfines".

Este periodo llega de modo agravado hasta la expedición de la Carta Política de 1991, pero previamente se pasa por la descomposición aterradora del orden público y de la seguridad del Estado, y se llega hasta la configuración de una especie de Estado inviable, aun bien entrada la última década del siglo XX y en los albores del siglo XXI.

15. Bajo el nuevo modelo constitucional de la Carta Política de 1991, el Consejo de Ministros sigue funcionando del mismo modo, y ahora los sucesivos gabinetes constitucionales han sido integrados con la participación personal y técnica de colaboradores políticos directos del presidente y de miembros de su grupo político; también han sido llamadas colaboraciones personales y técnicas de los conocidos personales del presidente y de los expresidentes, salvo durante el gobierno de Ernesto Samper Pisano en el que fue notoria la colaboración de representantes directos de los expresidentes liberales Turbay Ayala y López Michelsen ante la grave y persistente crisis de gobernabilidad por las investigaciones de la presencia de dineros de los narcotraficantes colombianos en su campaña y en la de sus amigos políticos en lo que se conoció como el "Proceso 8000 " que llevó a la cárcel a un buen número de senadores, representantes y directivos de sus campañas políticas.

16. En Colombia se produjo un fenómeno de ampliación y de flexibilización de los mecanismos de acceso a la personería jurídica de los seudo partidos y movimientos políticos, que se tradujo en la constitución de empresas artesanales y familiares de la política, con partidos de garaje y con las famosas operaciones avispa para lograr mayorías por vía de la fracción intrafamiliar.

\section{UN MUNDO QUE SE RECONSTRUYE}

1. El gobierno del Partido Liberal que propició la convocatoria de la Asamblea Constitucional, encontró la oportunidad para adoptar la mayor parte de las modificaciones aplazadas desde el fracaso de las dos reformas constitucionales de 1977 y 
1999; además, decidió proponer la plataforma programática del llamado Galanismo, movimiento acaudillado por el sacrificado líder Luis Carlos Galán, relacionada con la democracia participativa y de deliberación de una parte y el proyecto del gobierno de Virgilio Barco sobre derechos fundamentales de otra.

Además, los nuevos partidos de los varios grupos de ex guerrilleros reinsertados durante los gobiernos de Belisario Betancourt y Virgilio Barco aprovecharon semejante oportunidad para incorporar al texto constitucional buena parte de sus aspiraciones programáticas relacionadas con los mecanismos de participación democrática, los procedimientos reforzados para asegurar la reserva de ley en las materias más cercanas a la Carta Política de alto interés político y los elementos sociales de los derechos constitucionales y de sus mecanismos de protección; también incorporaron varias cláusulas programáticas, varios objetivos y fines constitucionales relacionados con los derechos económicos y sociales.

2. Advertimos de modo inicial que en el Régimen Político constitucional que se establece con la Constitución de 1991, las llamadas en el derecho constitucional comparado y especialmente en el derecho constitucional italiano y español, como leyes constitucionales u orgánicas respectivamente, en el régimen constitucional colombiano se denominan leyes estatutarias y se refieren a los mecanismos de participación democrática, a los estados de excepción, a la administración de justicia entre otras. ${ }^{26}$

26 El artículo 152 de la Carta Política de 1991 señala las materias que se regulan por este tipo de leyes, así: ART. 152. Mediante las leyes estatutarias, el Congreso de la República regulará las siguientes materias: a) Derechos y deberes fundamentales de las personas y los procedimientos y recursos para su protección; b) A dministración de justicia; c) Organización y régimen de los partidos y movimientos políticos; estatuto de la oposición y funciones electorales; d) Instituciones y mecanismos de participación ciudadana. e) Estados de excepción. f) Adicionado. A. L. 02/2004, Art. 4‥ La igualdad electoral entre los candidatos a la Presidencia de la República que reúnan los requisitos que determine la ley. PAR. TRANS. Adicionado. A. L. 02/2004, Art. 40. El Gobierno Nacional o los miembros del Congreso presentaran, antes del primero de marzo de 2005, un proyecto de ley estatutaria que desarrolle el literal f) del artículo 152 de la Constitución y regule además, entre otras, las siguientes materias: Garantías a la oposición, participación en política de servidores públicos, derecho al acceso equitativo a los medios de comunicación que hagan uso del espectro electromagnético, financiación preponderantemente estatal de las campañas presidenciales, derecho de replica en condiciones de equidad cuando el Presidente de la República sea candidato y normas sobre inhabilidades para candidatos a la Presidencia de la República.

El proyecto tendrá mensaje de urgencia y podrá ser objeto de mensaje de insistencia si fuere necesario. El Congreso de la República expedirá la ley estatutaria antes del 20 de junio de 2005. Se reducen a la mitad los términos para la revisión previa de exequibilidad del proyecto de ley estatutaria por parte de la Corte Constitucional.

Si el Congreso no expidiere la ley en el término señalado o el proyecto fuere declarado inexequible por la Corte Constitucional, el Consejo de Estado, en un plazo de dos (2) meses reglamentará transitoriamente la materia.

Con base en esta norma se han producido las siguientes leyes estatutarias: - Estatuto de los partidos y movimientos políticos, Ley 130 de 1994. - Voto programático, Ley 131 de 1994. - Libertad religiosa, Ley 133 de 1994. - M ecanismos de participación ciudadana, Ley 134 de 1994. - Estatuto de los estados de excepción, Ley 137 de 1994. - Ley estatutaria de la administración de justicia, Ley 270 de 1996. 
Se hace esta advertencia inicial, pues ellas juegan un papel sustancial en la evolución reciente de nuestro derecho constitucional y en su debate se han hecho notables inversiones de los recursos políticos del régimen.

3. Es posible afirmar que a pesar de las graves dificultades de orden público y de seguridad ciudadana que ha sufrido la República de Colombia, el modelo constitucional de justicia y especialmente de administración de justicia constitucional ha desarrollado de modo extraordinario y admirable el texto de la mencionada Constitución Política de 1991.

Así, también se observa que en actual Carta Política de los colombianos, vigente desde el 6 de julio de 1991, se introdujo un nuevo régimen de justicia constitucional, especialmente integrado por la Corte Constitucional como órgano de control concentrado de una parte y por la llamada acción de tutela como el instrumento procesal autónomo y directo previsto para promover la protección específica y directa de los derechos constitucionales fundamentales contra las acciones u omisiones de las autoridades públicas o de los particulares dentro de las instituciones del llamado control difuso. ${ }^{27}$

27 La regulación de las funciones judiciales de la Corte Constitucional se encuentra en el artículo 241. A la Corte Constitucional se le confía la guarda de la integridad y supremacía de la Constitución, en los estrictos y precisos términos de este artículo. Con tal fin, cumplirá las siguientes funciones: 1. Decidir sobre las demandas de inconstitucionalidad que promuevan los ciudadanos contra los actos reformatorios de la Constitución, cualquiera que sea su origen, sólo por vicios de procedimiento en su formación. 2. Decidir, con anterioridad al pronunciamiento popular, sobre la constitucionalidad de la convocatoria a un referendo o a una asamblea constituyente para reformar la Constitución, sólo por vicios de procedimiento en su formación. 3. Decidir sobre la constitucionalidad de los referendos sobre leyes y de las consultas populares y plebiscitos del orden nacional. Estos últimos sólo por vicios de procedimiento en su convocatoria y realización. 4. Decidir sobre las demandas de inconstitucionalidad que presenten los ciudadanos contra las leyes, tanto por su contenido material como por vicios de procedimiento en su formación. 5. Decidir sobre las demandas de inconstitucionalidad que presenten los ciudadanos contra los decretos con fuerza de ley dictados por el Gobierno con fundamento en los artículos 150 numeral 10 y 341 de la Constitución, por su contenido material o por vicios de procedimiento en su formación. 6. Decidir sobre las excusas de que trata el artículo 137 de la Constitución. 7. Decidir definitivamente sobre la constitucionalidad de los decretos legislativos que dicte el gobierno con fundamento en los artículos 212, 213 y 215 de la Constitución. 8. Decidir definitivamente sobre la constitucionalidad de los proyectos de ley que hayan sido objetados por el gobierno como inconstitucionales, y de los proyectos de leyes estatutarias, tanto por su contenido material como por vicios de procedimiento en su formación. 9. Revisar, en la forma que determine la ley, las decisiones judiciales relacionadas con la acción de tutela de los derechos constitucionales.10. Decidir definitivamente sobre la exequibilidad de los tratados internacionales y de las leyes que los aprueben. Con tal fin, el gobierno los remitirá a la Corte, dentro de los seis días siguientes a la sanción de la ley. Cualquier ciudadano podrá intervenir para defender o impugnar su constitucionalidad. Si la Corte los declara constitucionales, el gobierno podrá efectuar el canje de notas; en caso contrario no serán ratificados. Cuando una o varias normas de un tratado multilateral sean declaradas inexequibles por la Corte Constitucional, el Presidente de la República sólo podrá manifestar el consentimiento formulando la correspondiente reserva. 11. Darse su propio reglamento.

PAR.- Cuando la Corte encuentre vicios de procedimiento subsanables en la formación del acto sujeto a su control, ordenará devolverlo a la autoridad que lo profirió para que, de ser posible, enmiende el defecto observado. Subsanado el vicio, procederá a decidir sobre la exequibilidad del acto. 
4. Sin que esta sea la oportunidad para examinar la totalidad de las instituciones constitucionales que hacen parte de la Carta Política de 1991, es indispensable advertir que el resultado de los trabajos de la A samblea Constituyente en estas materias es considerado como uno de los más importantes esfuerzos de actualización y de recomposición de un régimen político en América Latina.

Ello no significa que el cambio constitucional comprenda, defina y resuelva de inmediato el tema del cambio político que muchos esperaron una vez puesto en marcha el mecanismo directo y originario de la Asamblea Constituyente.

Hemos sostenido al respecto en varios escritos precedentes que en nuestro país se produjo el más notable cambio constitucional de toda su historia pero que este no significó el cambio político que muchos esperaron; es más creemos que para lograr ese cambio aun hacen falta varios procesos políticos de reforma institucional y de la superación de obstáculos institucionales como los que impone el celo entre las altas cortes por su supremacía como guardianes de los varios modelos de estado y de justicia.

5. No sobra advertir que precisamente en los treinta años que examinamos en este coloquio, las sociedades han sido y aún son objeto de una nueva revolución política, cultural, industrial y económica, últimamente de naturaleza cibernética, informática y electrónica, y que en ellas se presentan fenómenos sociales y culturales de amplio efecto sobre el derecho en todos sus órdenes, especialmente en el derecho constitucional; éstos se desarrollan con mayor énfasis en unos regímenes político-constitucionales como en el caso de la Constitución de Colombia de 1991.

Más adelante haremos un listado breve y de resumen de las más importantes transformaciones constitucionales introducidas por la actual constitución en materia de la forma de estado, de la noción de soberanía, del régimen político y de partidos, de los controles al poder, de la organización del Estado, de la rama Judicial, de la justicia constitucional, de las libertades públicas y de los derechos constitucionales.

Estos fenómenos o movimientos y su dinámica histórica no son, de ninguna mane$\mathrm{ra}$, asuntos acabados, y la reconstrucción del orden aún sigue con vigor gracias o por fuerza de la mundialización del capital, la internacionalización y la regionalización de los procesos productivos, la desregulación internacional, la apertura e integración de mercados y su unificación, la privatización de empresas y de beneficios públicos, la participación y la colaboración de los particulares en la prestación de servicios públicos tradicionales, las desregulaciones internas y el cumplimiento de funciones públicas por organizaciones privadas de diverso orden y la profunda y generalizada crisis del Estado de bienestar y del Estado asistencial.

6. Debemos advertir que en este sentido los dos últimos gobiernos en Colombia, es decir, los de Andrés Pastrana A rango y Álvaro Uribe Vélez, han puesto énfasis en la reducción del tamaño del Estado y de la administración pública en todos los niveles territoriales, y en el traslado de buena parte de los viejos negocios estatales a los 
particulares, como es el de grupos de empresas de servicios públicos domiciliarios o masivos y de las entidades dedicadas a atender los deberes asistenciales y de seguridad social de los colombianos.

Hoy, casi todos estos servicios se encuentran en manos de particulares, quienes los prestan como un negocio especial vigilado por el Estado y ampliamente afectado por las decisiones de la jurisdicción constitucional, en aplicación de la institución de la acción de tutela para el amparo de los derechos fundamentales a dignidad humana, la salud, la integridad física y la vida, entre otros, como el derecho a las pensiones.

Además, la mayor parte de los puertos, aeropuertos, carreteras, autopistas, oleoductos y gasoductos, los canales de televisión y la explotación del espectro electromagnético, están en manos de empresas privadas y en buena parte de inversores y empresas extranjeras, con poca participación de nacionales particulares.

7. Además el predominio evidente que se vivió durante estas tres décadas de las economías de mercado, abiertas y desreguladas ha replanteado algunos elementos de las reformas de las constituciones de la década de los noventa, especialmente en lo que hace a la introducción de reglas de solidaridad, universalidad y generalidad que plantean la existencia de un modelo de economía social de mercado que permite altos grados de intervención y orientación pública de los recursos;

Todo ello ha planteado de nuevo el tema del vigor y de la eficacia del derecho constitucional y en algunos países la necesidad de nuevas reformas constitucionales que permitan orientar y cautelar las injusticias sociales y el desequilibrio económico.

Es evidente entre nosotros el desarrollo de las nuevas disciplinas del derecho público que tiene su origen en el derecho constitucional, especialmente en áreas como las del derecho de la seguridad social, el derecho de las telecomunicaciones, de los recursos naturales, el derecho ambiental, económico de la infraestructura y el de las concesiones.

Obviamente, la revolución electrónica, informática, telemática y cibernética, los grandes sistemas de formación de opinión pública, el impacto de los desechos industriales y tecnológicos y la contaminación del ambiente, replantean algunas de las más importantes expectativas espirituales y estas se proyectan de varias maneras en el derecho constitucional; ellas fueron recogidas inicialmente y en buena parte por la Carta Política de 1991, luego, por sus desarrollos legales y por la jurisprudencia de la Corte Constitucional de Colombia.

8. En el año de 1990, ni los jóvenes estudiantes que conformaron el movimiento de la Séptima Papeleta, ni los integrantes de la Corte Suprema de Justicia, ni el gobierno mismo, tenían en mente la estructuración de un proyecto político del alcance y las dimensiones del que resultó finalmente con la expedición de la Carta Política de 1991. 
M enos se imaginaban que de aquella Corte resultaría la oportunidad de sustituir la mayor parte de los componentes del régimen político colombiano y la posibilidad de modificar las bases esenciales y la estructura del modelo constitucional de la economía y de la hacienda pública que venía formulado desde 1886, con las reformas introducidas en 1936, 1945 y 1968.

Quienes participaron en aquellos insólitos ejercicios político judiciales, aun en el más alto nivel de su muy escaso optimismo, sólo suponían y esperaban un resultado relativamente menor y plenamente controlable por los varios actores orgánicos del régimen político. Lo cierto es que sólo al final y después de las dos sonadas y consecutivas sentencias de "exequibilidad parcial", dictadas por la Corte Suprema de Justicia reintegrada cuatro años antes, se permitió la reunión y la transfiguración de la proyectada Asamblea Nacional Constitucional en una Asamblea Nacional Constituyente, absolutamente desatada de frenos normativos preexistentes, capaz de expedir una nueva Carta Constitucional, y de configurar un nuevo modelo de Estado.

\section{LAS DOS ETAPAS DE ESTE PERÍODO}

1. Como lo señalamos, este periodo puede dividirse en Colombia en dos partes, así:

a. De 1976 a 1990, que hemos llamado de Cierre y de Bloqueo Institucional. Caracterizado por la continuidad del régimen bipartidista, inicialmente el Congreso de la República y, especialmente, en la rama judicial del poder público y en la mentalidad de las clases dirigentes del país, organizadas en torno de los dos partidos tradicionales y de sus autofraccionamientos locales.

A pesar de que este es un periodo en el que continúa lánguido pero efectivo el modelo del gobierno para la anormalidad y para la excepción, la descomposición y la alteración del orden público y la seguridad ciudadana fueron inmensas y casi absolutas.

Se mencionará más adelante la introducción de un número menor de reformas fracasadas por fuerza del control de constitucionalidad a las reformas constitucionales ${ }^{28}$ y sólo algunas reformas indemnes como son la de la disminución de la edad para la ciudadanía y la de la elección popular de alcaldes o de la mal llamada democracia local.

b. De 1991 al 2005, llamado del Cambio Constitucional y de Consolidación del Nuevo Modelo de Estado. Este periodo termina con la aprobación de la reforma constitucional que permitió por primera vez en la historia nacional la reelección inmediata del Presidente de la República, en cabeza de Álvaro Uribe Vélez.

En esta última etapa o periodo de evolución político constitucional de Colombia, también se encuentra una notable tarea de elaboración de proyectos de reformas y de

28 Las dos reformas a la Constitución de 1886 que fueron declaradas inconstitucionales son las de 1977 impulsada por el Gobierno de Alfonso López y la de 1979 tramitada por el Gobierno de Julio César Turbay. 
reformas efectivamente introducidas a los textos constitucionales de la Carta Política de 1991, la mayor parte de los cuales se refiere en general al funcionamiento del régimen político, a la extradición de nacionales, a la expropiación sin indemnización por razones de equidad, a los regímenes de transferencias de recursos fiscales de las entidades territoriales, al régimen de justicia penal y a las instituciones de la democracia representativa y de elecciones.

Especial consideración se hace en relación con el notable cúmulo de reformas introducidas durante este periodo a los regímenes de requisitos, calidades, inhabilidades e incompatibilidades para quienes aspiran a los más altos destinos públicos, al régimen de elección y de organización y funcionamiento de los partidos políticos, a la organización electoral, al régimen de personería jurídica de los partidos políticos y a su organización interna y a su funcionamiento.

En esta materia también se introdujo el régimen del voto preferente, la lista única, y la cifra repartidora y el régimen de disciplina de bancadas de los partidos en las cámaras del Congreso de la República.

2. A pesar de encontrarse por fuera del período que examinamos en esta ponencia, cabe mencionar la reciente reforma al régimen de la moción de censura a los ministros del Gobierno Nacional y a los secretarios de los gobiernos distritales, municipales y departamentales (2007) en una especie reforzada del control del poder legislativo al poder ejecutivo.

3. Como lo veremos más adelante, durante el anterior periodo de la vida constitucional y política que se configuró entre 1976 y 1991 en medio de una de las más dolorosas tragedias, la República de Colombia vivió un proceso largo y complejo de diseño y de intentos de construcción de un nuevo modelo de régimen político, que en principio debía estar orientado hacia la apertura democrática y modernidad constitucional, en los ámbitos territorial y fiscal y específicamente dotado de recursos institucionales para resolver los problemas de ingobernabilidad, del bloqueo progresivo y de la inestabilidad política, para sustituir el esquema cerrado del bipartidismo tradicional conocido como el Frente Nacional (1958-1974).

4. La principal dificultad que había sufrido el sistema político colombiano y que se debía superar en esos años de frustrados intentos de reforma, fue el de la violencia política y terrorista, ejecutada por grupos de guerrillas y de narcotraficantes organizados en bandas de alcance internacional, muy agresivos, osados y con amplios recursos económicos Para Restrepo Pedrahita (1998), "Todo el complejo de circunstancias político-constitucionales que informa el proceso político-institucional interno en la segunda mitad del siglo XX colombiano se enmarca en las anómalas coordenadas desestabilizadoras de las guerrillas y el narcotráfico". ${ }^{29}$

29 Restrepo Piedrahita, Carlos (1998), "Evolución Constitucional en el siglo XX", en Memorias del Congreso Iberoamericano de Derecho Constitucional, Tomo I, Ed. U. Externado de Colombia, p. 322. 
5. Los temas de las frustradas agendas de gobernabilidad durante ese periodo fueron, principalmente, el tema de la reforma a la justicia, la modernización de la administración territorial, la reforma al Congreso y el régimen de elecciones; además, la creación del Consejo de la Magistratura, la Fiscalía General de la Nación, la aplicación de la carrera judicial, la asignación de funciones y competencias de autogobierno a los departamentos y municipios, la representación de las minorías, entre otros, coparon las propuestas de reforma constitucional.

Los mencionados cometidos orgánicos e institucionales se lograron en el desarrollo de las actividades de la Asamblea Constitucional de 1991 y su vigencia ha signado la vida del régimen político nacional en los últimos quince años (1991-2005); por ello, las nuevas instituciones y las modificaciones a dicha estructura se encaminan a promover su modernización y la gobernabilidad democrática, como son la creación de nuevos órganos de control y de organismos y entidades autónomas e independientes.

Ello responde igualmente a la necesidad de garantizar mayores niveles de neutralidad e independencia de la gestión pública, en la búsqueda de mayores niveles de satisfacción de las necesidades colectivas y de mayor legitimidad de las autoridades.

6. Ni el gobierno del presidente César Gaviria recién inaugurado, ni los partidos tradicionales, ni los partidos y movimientos nuevos, todos golpeados por el sacrificio de sus dirigentes, estaban preparados dogmáticamente para provocar aquellos cambios y transformaciones; sólo había circulado, al lado de los proyectos que habían hecho parte de la frustrada reforma constitucional de 1979, el nuevo proyecto preparado para el gobierno Barco (1986-1990) por Carlos Restrepo Piedrahita, sobre los derechos constitucionales fundamentales y su protección especializada, lamentablemente sacrificado por la invasiva presencia de los narcotraficantes en el recinto de la democracia constitucional. También habían circulado las propuestas de la campaña política de Luis Carlos Galán relacionadas con la democracia participativa, con la política de recursos naturales y de fronteras, con el régimen de partidos y con los derechos sociales.

7. Este régimen, ciertamente, había sido dura y dolorosamente castigado por el accionar de los grupos y las bandas de criminales de diversa etiología, ideología y moral, todos fortalecidos con los recursos del narcotráfico colombiano y transnacional y se encontraba profundamente resentido y muy debilitado.

8. El movimiento estudiantil de la Séptima Papeleta había propuesto como fundamento de sus aspiraciones constitucionales la reforma a la justicia y la modificación del régimen de partidos y de la democracia representativa; no obstante la prudencia inicial, la sentencia de la Corte Suprema dio lugar y fundamento para un cambio constitucional integral y complejo como el que se expresa a través de la Carta Política de los colombianos de 1991.

La débil mayoría de la Sala Plena de la Corte Suprema de Justicia, reunida en las dos oportunidades procesales correspondientes en ese año admitió la reunión de ese 
órgano sin más límites formales que lo que llamó el respeto a los periodos de los órganos constitucionales de origen democrático, es decir aquellos para los que por su origen electoral no se podían decretar revocatoria ni disoluciones. ${ }^{30}$

9. La realidad económica, política, social y cultural aún dista sustancialmente de las condiciones objetivas requeridas, a tal punto que no se ha logrado siquiera implantar todavía un verdadero Estado de Derecho en algunas partes del territorio nacional. Todavía se trata de una sociedad excluyente y fragmentada que no ha logrado cohesionar al conjunto de los ciudadanos en torno de un proyecto colectivo y aun encontramos prácticas criminales y terroristas capaces de desafiar a las autoridades judiciales y de policía; se trata de la existencia de un modelo de desarrollo que no ha incorporado productivamente a gran parte de la población en la vida social y económica de la nación, de la crisis de lo político como instrumento colectivo de construcción de un orden social a partir de su función de representación y expresión de los intereses, problemas y tensiones de la sociedad, y de un Estado ineficaz para el cumplimiento de sus responsabilidades básicas y en ocasiones suplantado por intereses privados poderosos.

10. A diferencia del subdesarrollo endémico del derecho constitucional colombiano, al que se refería Restrepo Piedrahita como uno de los problemas que enfrentaron los estudiosos colombianos en esta materia, no sólo para la época sobre la que adelantó su estudio sino en el pasado, el periodo reciente y que examinaremos aquí, es el más vigoroso en la creación y el desarrollo de la jurisprudencia constitucional y de la expansión de la doctrina de este derecho.

11. En desarrollo de la metodología acordada, en esta oportunidad me ocuparé de examinar los aspectos singulares de la notable evolución político-constitucional del país y de su sistema de gobierno; además presentaré los avances y las amenazas a la democracia colombiana en esos treinta años, los derechos fundamentales, el poder judicial y el tribunal constitucional, los mecanismos de defensa de la Constitución y de los partidos políticos.

En el nuevo contexto de la doctrina del Derecho Constitucional que se encuentra en pleno desarrollo en Colombia a partir de 1991, encontramos una nueva aproximación a los temas contemporáneos de Estado y del gobierno y ella se traduce en la mayor parte de los recientes procesos de reforma constitucional que veremos más adelante.

\section{LAS ÚLTIMAS REFORMAS A LA CONSTITUCIÓN DE 1886}

1. Después de los graves y sangrientos acontecimientos de 1948 en los que fue sacrificado el líder político liberal Jorge Eliécer Gaitán y en los que se produce el movi-

30 De la CAlLe, Humberto (2004), Contra todas las apuestas. Historia íntima de la Constituyente de 1991 (Bogotá, Editorial Planeta Colombiana). 
miento popular y la situación de asalto y pillaje denominada "El Bogotazo", y por la dolorosa situación de violencia bipartidista generalizada, acompañada de la más extensa suspensión de la normalidad constitucional, los colombianos quedamos rezagados en la primera versión del Estado Social de Derecho de la República Weimar y de la Constitución A ustriaca, según los términos de nuestra reforma constitucional de 1936.

Esta reforma, desde luego, social e intervencionista fue interpretada por la Corte Suprema de Justicia llamada Corte de Oro, y desarrollada en los contenidos de la reforma de 1945 que incorpora la noción de planeación económica y la de leyes orgánicas y redefine la noción de intervencionismo de Estado.

En efecto, en nuestro país se produjo un proceso de cierre y de bloqueo progresivo en el régimen constitucional con la fuerza de un plebiscito abrumador, situación que se prolonga hasta la reunión del constituyente de 1991 por razones de orden político propias del sistema mismo.

Esto marginó al derecho nacional de las grandes tendencias del derecho constitucional en el mundo, que, precisamente, comienzan a desarrollarse y a difundirse en todo Europa y en algunos países de América Latina con la expedición de las constituciones pluralistas de Italia y de Francia y de la Ley Fundamental de Bonn, con la nueva versión del Estado Social y Democrático de Derecho y con las nuevas herramientas de la justicia constitucional de los derechos fundamentales.

2. En realidad, mientras durante el siglo XX en todo el mundo el derecho constitucional adquiría dimensiones extraordinarias y novedosas, con las salvedades de los dos periodos de guerras en Europa, a partir de 1948 mantuvimos un sistema político extremadamente rígido y refractario al cambio y al desarrollo, y conservamos un régimen constitucional vinculado a nociones y a cláusulas superadas por el derecho después de la desaparición de las dictaduras fascista y nacionalsocialista. De todo ello da cuenta el mencionado informe de nuestro profesor Carlos Restrepo Piedrahita.

3. Desde luego, con la reforma de 1968, predominantemente tecnocrática y presidencialista, se modernizó en parte el capítulo de organización de la administración centralizada y descentralizada y con la reforma de 1986 se introdujo la elección popular de alcaldes; claro está, como lo explicaremos más adelante, siempre se debe advertir que con los dos intentos fallidos de las reformas de 1977 y 1979, se pretendía incorporar algunos de los más destacados avances en estas materias, pero ambos resultaron frustradas por razones de carácter "político y técnico" que han sido materia de fuertes criticas por la mayor parte de los actores del régimen político nacional.

4. Si bien es cierto que al sistema jurídico vigente hasta 1991 se incorporaron por vía legal algunas modificaciones en varias áreas del derecho, como en el procesal civil, de familia y del menor, en el de las entidades territoriales y en el urbanístico, del medio ambiente, monetario, fiscal y en el electoral, éstas sólo encuentran en la Constitución vigente una respuesta vigorosa y eficaz en institutos jurídicos y en figuras 
novedosas, pues en ella se recogen los más recientes desarrollos sobre la legitimidad del Estado, los derechos, las libertades y los procedimientos para su protección, la organización política, y en especial sobre el modo de configuración jurídica del Estado democrático avanzado dentro de una sociedad post-igualitaria.

5. Una vez terminado el anterior periodo de evolución político constitucional que examina el profesor Restrepo Piedrahita en su ponencia, en la República de Colombia encontramos una corta serie de reformas introducidas al texto de la Constitución de 1886, que se refieren específicamente a elementos de orden político de variada importancia, vigencia y extensión, casi todas relacionadas con la reorganización incidental y menor del régimen político de una parte, y con la administración de justicia y la administración territorial de otra. Unas de aquellas fueron aprobadas y aplicadas con pleno vigor a pesar de su poca importancia, y otras resultaron frustradas en escenarios imprevistos y supremamente costosos para el desarrollo democrático y para la modernización de las instituciones del régimen político constitucional.

Salvo la reforma de 1986 sobre la elección popular de alcaldes y las nuevas instituciones de la llamada democracia local que se pudieron introducir el régimen político colombiano durante el gobierno de Belisario Betancourt, las demás son retoques menores que contrastan con la progresiva y dolorosa descomposición del orden público interno por fuerza del crecimiento de las varias guerrillas, FARC, ELN, EPL, de los grupos y carteles de narcotraficantes y de las varias bandas de paramilitares. Todos ellos desataron oleadas y campañas de expansión y de exterminio de actores y acciones criminales, selectivas y terroristas, de desestabilización del orden constitucional.

A unque varios autores alcanzaron a señalar la existencia de ordenes paralelos y hasta de "Paraestados" en nuestro ternitorio, lo cierto es que las organizaciones de las guerrillas y de los paramilitares alcanzaron a controlar de modo relativo partes del territorio de la república, especialmente, en las zonas selváticas del sur oriente del país y a incursionar en casi todo el territorio nacional con acciones intermitentes y esporádicas.

6. De estas últimas, cabe señalar que buena parte de sus propuestas luego fueron recuperadas por la reforma constitucional de 1986 sobre elección popular de alcaldes y de democracia local de una parte, y por la nueva Carta Política de 1991, de otra, que, con expresa intención de sustraerse a el examen del viejo poder judicial, prohibió el control de constitucionalidad en su caso, que, además, le retiró dichas competencias a la Corte Suprema de Justicia y creó la Corte Constitucional.

Hartlyn (1994) advierte que "... la rigidez del acuerdo del Frente Nacional no sólo reflejaba un deseo de desmovilización tras la intensa ola de violencia que sacudía al país, sino también los temores a un potencial abuso de poder por un partido que controlase el unitario sistema presidencial". ${ }^{31}$

31 HaRTLYN, Jonathan (1998), El presidencialismo y la Política Colombiana, en Las crisis del Presidencialismo, Volumen 2. El caso latinoamericano (M adrid, Ed. Alianza Universidad), p. 228. 
En todo caso tanto es evidente el sentimiento de rigidez constitucional y de endurecimiento del régimen político colombiano, así como de extrema desconfianza entre los varios actores institucionales del sistema que, a pesar de proponerse el establecimiento transitorio y relativamente breve del Frente Nacional, se hizo todo lo posible por mantenerlo y por extenderlo a pesar de los altos costos que esto significó para el avance social, la paz y orden público. También es evidente que todo ese andamiaje institucional del régimen político colombiano es en gran parte causa de la descomposición social y de la exclusión de muchos grupos y actores políticos disidentes.

Cabe recordar que el control de constitucionalidad de las leyes, la elección de todos los magistrados y jueces y la auto integración de la rama judicial en la República de Colombia tenían como depositario de todo el poder judicial a la Corte Suprema de Justicia y al Consejo de Estado, integrados de modo paritario y milimétrico por representantes de los dos partidos tradicionales, pero compuesta por medio de la figura de la cooptación plena. Dicha competencia no comprendía expresamente las del control de constitucionalidad de las reformas constitucionales expedidas por el congreso de la república en desarrollo de sus funciones de poder derivado de reforma constitucional, pero significaron muy profundos obstáculos a los varios intentos de modificación de las reglas de funcionamiento del aparato estatal, especialmente en el tema de la administración de justicia y de la democracia local.

Precisamente, las reformas que denominamos frustradas, habían sido adoptadas en el consenso de las fracciones mayoritarias de los dos partidos políticos tradicionales para modificar el régimen de administración de justicia y para reorganizar el régimen territorial, foco de graves conflictos internos al impedir la renovación de las elites y de las clases y grupos dirigentes locales; la inconstitucionalidad de las mismas despojó de aquellos recursos institucionales al régimen político y a la administración de justicia.

7. La mayor parte de las reformas constitucionales que examinaremos enseguida, a pesar de expedirse aparentemente en la vía del llamado "Desmonte del Frente Nacional", en verdad pertenecen a un periodo de nuevos esfuerzos de reafirmación y endurecimiento del bloqueo institucional y de reforzamiento de las reglas superiores de la cuasi democracia que se configuró con el establecimiento del mencionado régimen para salir de la dictadura militar establecida en 1953 y que se extiende hasta 1958.

A demás, a ello contribuyó la insólita e inédita práctica de declarar inconstitucionales las reformas constitucionales por inadvertidos y supuestos vicios sustanciales como el desconocimiento de la existencia de decisiones políticas fundamentales y de cláusulas pétreas de reforzamiento del valor de partes de la Constitución, como en el caso de la reforma de 1977 y por la aparición de vicios de procedimiento de orden reglamentario interno y de naturaleza legal como se predicó de la reforma de 1979.

8. Según HARTLYN (1998), "El acuerdo original del Frente Nacional pactado entre los principales dirigentes políticos, que entró a formar parte de la Constitución por medio de un plebiscito nacional, pretendía encarar los peligros del presidencialismo 
mediante una perfecta paridad entre los dos partidos en todas las ramas del gobierno durante dieciséis años y mediante la despolitización de la administración pública. También se acordó que un conservador se hiciera cargo del primer mandato presidencial. Sin embargo, las divisiones en el seno del Partido Conservador llevaron a la candidatura de un liberal para ese primer mandato y a un acuerdo para que el Congreso aprobara la reforma constitucional mediante la cual instituir la alternancia para los tres mandatos siguientes. La necesidad de englobar formalmente el acuerdo sobre el reparto del poder en el marco de la Constitución fue una consecuencia del presidencialismo y del hecho de que los líderes nacionales no podían controlar el surgimiento de listas disidentes potencialmente victoriosas opuestas al acuerdo". ${ }^{32}$

Como se advirtió más arriba, aquellos supuestos del régimen político constitucional fueron los de la repartición bipartidista de todos los cargos públicos incluidos los de la rama judicial y las curules de las cámaras del Congreso de la República, la forzada alteración excluyente de los dos partidos tradicionales en la participación de los candidatos a la Presidencia de la República desde 1962 hasta 1978 en periodo que examinaremos enseguida.

No sobra recordar la ocurrencia de los problemas de carácter electoral y de orden público con las irregulares y cuestionadas elecciones de 1970 en las que perdió la ANAPO, grupo acaudillado por el General Rojas Pinilla y obtuvo la Presidencia de la República el candidato conservador M isael Pastrana Borrero; todo ello generó la crisis y el sentimiento de frustración política que agudizó el bloqueo político bipartidista y muy posiblemente el surgimiento del grupo M19 tan costoso para la continuidad institucional colombiana y para la paz de la sociedad, desde luego sin examinar los acontecimientos de la toma y recuperación militar del palacio de justicia.

HARTLYN (1998) considera que dada la falta de diferencias nítidas entre los dos partidos, el declive de la identificación sectaria entre ellos, los largos años de gobiernos de coalición, la naturaleza del procedimiento electoral que permitía múltiples listas de cada partido, y el mantenimiento de las prácticas clientelistas en un contexto de elevada abstención, el problema era que las elecciones no canalizan eficazmente la oposición política ni permitía la renovación social en un país tan complejo y abigarrado como Colombia. ${ }^{33}$

\section{Las mencionadas reformas son:}

a. El Acto Legislativo $\mathrm{N}^{\circ} 1$ de 18 de diciembre 1975 por el cual se modifican los artículos 14, 15 y 171 de la Constitución Nacional que introdujo la reducción de la edad para adquirir la ciudadanía de los veintiún años, que se exigían antes de la refor-

32 HaRTrYN, Jonathan (1998), "El presidencialismo y la Política Colombiana”, en Las crisis del presidencialismo, Volumen 2. El caso latinoamericano (Madrid, Ed. Alianza Universidad), p. 224.

33 HaRTLYN, Jonathan (1998), "El presidencialismo y la Política Colombiana", en Las crisis del Presidencialismo, Volumen 2. El caso latinoamericano (Madrid, Ed. Alianza Universidad), p. 226. 
ma, a la de dieciocho para hombres y mujeres que aún rige en nuestro país; el trámite de esta reforma comenzó durante el gobierno conservador del presidente M isael Pastrana y desde luego significó un importante elemento de expansión de las instituciones democráticas en nuestro régimen político, a pesar de que se sostuvo que su contenido podría favorecer al cúmulo de votantes del Partido Conservador con fuerte arraigo en las familias campesinas y tradicionales de provincia que se mantenían unidas durante más tiempo que las de las ciudades favorecedoras del electorado del Partido Liberal. ${ }^{34}$

b. El Acto Legislativo $N^{\circ} 1$ de 11 de febrero de 1977 que reorganizó las instituciones de los reemplazos del Presidente de la República, especialmente durante sus viajes al exterior en ejercicio de funciones presidenciales y la creación de la figura del ministro delegatario; el régimen de faltas absolutas y temporales del Presidente de la República; el régimen de los permisos y los informes para salir del país el presidente y los expresidentes de la República y de algunas reformas a las competencias especiales del Senado de la República. ${ }^{35}$ Durante dicho gobierno dos jefes liberales adquirieron la condición de expresidentes por ocupar en breve tiempo la presidencia por viajes del titular del poder ejecutivo.

Se quiso evitar la atribución del titulo y el rango de expresidentes a quienes la ejercían de modo breve y transitorio a titulo de designados a la presidencia, entre otras argumentaciones con base en la idea de la austeridad en el gasto público de las pensiones otorgadas automáticamente.

c. La reforma introducida por el Acto Legislativo $\mathrm{N}^{\circ} 2$ del 19 de diciembre de 1977, promovida directamente por el gobierno del presidente Alfonso López Michelsen conocida como la de la pequeña constituyente; esta decisión del poder constituyente colombiano fue declarada contraria a la Constitución de 1886, en los textos incorporados por el llamado plebiscito de 1957, en los que se advertía que en adelante las reformas a la Constitución sólo podían ser decretadas por actos del poder legislativo ordinario, para evitar la reunión de asambleas constituyentes corporativas como la convocada por la dictadura militar del General Rojas Pinilla.

A pesar de haber estado vigente la mayor parte o casi toda la reforma fue retirada del ordenamiento constitucional y no pudo operar; a estas alturas del desarrollo de la historia constitucional de Colombia es explicable el poco destino y la ausencia de viabilidad de la reforma.

34 El texto de la citada reforma advertía que: «Son ciudadanos los colombianos los mayores de 18 años. La ciudadanía se pierde de hecho cuando se ha perdido la nacionalidad. También se pierde o se suspende, en virtud de decisión judicial, en los casos que determinen las leyes. Los que hayan perdido la ciudadanía podrán solicitar rehabilitación».

35 En Colombia se emplea la expresión Acto Legislativo para denominar los actos de reforma constitucional expedidos por órganos de carácter legislativo o constituyente como el Congreso de la República o Asamblea Constituyente. 
En el texto de esta frustrada reforma, el gobierno propuso la convocatoria y reunión de una "Pequeña A samblea Constitucional" para que funcionara durante un año a partir del 15 de julio de 1978, es decir durante parte del último mes del gobierno de Alfonso López Michelsen y durante el primer año del siguiente gobierno constitucional (1978 a 1982) que le correspondió a Julio César Turbay Ayala, representante del partido liberal y también primer presidente elegido después de pasado el último de los periodos de los presidentes de alternación bipartidista.

Los temas de los que debía ocuparse la A samblea Constitucional serían los de la administración departamental y municipal, el ministerio público, la administración de justicia y la jurisdicción constitucional y demás normas relacionadas; desde luego temas de la mayor importancia para el modelo de gobierno y para el régimen político colombiano, especialmente para los fueros y poderes de la rama judicial.

Resulta que en la mencionada reforma declarada inconstitucional por la Corte Suprema de Justicia se asignaba por primera vez y de modo expreso la competencia para el control de constitucionalidad de las reformas constitucionales y de modo especial y automático para conocer de la constitucionalidad de los actos reformatorios expedidos por la Asamblea Constitucional.

La Corte Suprema declaró que el artículo 14 de esta reforma no era contrario a la constitución y éste se salvó de ser retirado del ordenamiento constitucional; en aquel se estableció la regla aún vigente de la separación de las fechas de las elecciones para congreso y para Presidente de la República; esta regla depuró, sólo en una muy pequeña parte, algunos de los elementos de descomposición del régimen político y del presidencialismo restringido del modelo colombiano, por la necesaria interdependencia de los elegidos entre sí.

El candidato del partido a la presidencia en algunos casos decidía quiénes podían llegar al congreso por su partido, pero, al mismo tiempo, aquellos hacían la verdadera tarea electoral para quedar habilitados y pasar las cuentas de cobro en materia de gobernabilidad, clientelas y demás costos al gobierno central. Con esa reforma se pretendía terminar la dependencia del presidente de los caudillos y jefes locales y de estos del poder a aquel (Sentencia del 5 de mayo de 1978 de la Corte Suprema de Justicia Sala Plena).

d. La otra de las dos frustradas reformas a la Constitución es la de 1979, expedida por el Congreso de la República mediante el acto legislativo $N^{\circ} 1$ de diciembre 4 de ese año y conocida como la más extensa y costosa modificación al régimen político colombiano establecido en la Constitución de 1886 y sus posteriores evoluciones como las del Frente Nacional.

Esta reforma fue promovida e impulsada por el gobierno del presidente Julio César Turbay, con el apoyo de la mayor parte de los integrantes del Partido Conservador, especialmente por su dirigente principal, Álvaro Gómez Hurtado. El gobierno empleó 
buena parte de sus recursos políticos y, salvo algunas fracciones del Partido Conservador y del Partido Liberal, encabezadas por dos expresidentes de la República, logró integrar un texto de aparente consenso que entró en vigencia de modo progresivo.

Con aquella se pretendía modificar radicalmente el régimen del gobierno y administración de la justicia con la supresión de la cooptación y de la paridad, el establecimiento de la carrera judicial, la creación del Consejo Superior de la Judicatura, la creación y el desarrollo del régimen penal acusatorio con la Fiscalía General de la República; la modificación al régimen de control de constitucionalidad de las leyes y de los demás actos normativos de orden superior equiparables y con la caducidad de las acciones de inconstitucionalidad por vicios de forma en el trámite de las reformas constitucionales. A demás, se establecía la regla de la destinación del $10 \%$ del presupuesto de la rama judicial y del ministerio público.

En esta reforma con sesenta y cinco artículos que modificó otra buena cantidad de disposiciones constitucionales, se establecieron reglas para modernizar el funcionamiento del Congreso de la República con nuevo régimen de quórum y de mayorías, para hacerlo más funcional, con nuevas atribuciones de indagación y de instrucción de investigaciones especiales, con la introducción de la pérdida de investidura de los congresistas.

Por primera vez se establecían una especie de independencia funcional y técnica de la Junta Directiva del Banco Central y la posibilidad de reglamentar los partidos políticos y la financiación de los gastos electorales; también se permitía al Congreso de la República dar voto de aplauso y de censura a los actos oficiales y se permitía la aprobación de la llamada moción de observaciones a los ministros.

Como advertimos, en la sentencia de 3 de noviembre de 1981 se declaró la inconstitucionalidad de la citada reforma por supuestos vicios de trámite en la acumulación reiterada de diversos proyectos de reforma constitucional; es decir, la Corte Suprema de Justicia que se autoproclamó competente para juzgar la constitucionalidad de las reformas constitucionales, encontró que la violación del reglamento interno del Congreso de la República en el trámite de la citada reforma de la Constitución por la acumulación indebida de proyectos contrariando el reglamento interno y por ello violando la Constitución misma.

Cabe reiterar la advertencia que se hace sobre las costosas consecuencias de ese fallo para la modernización de la democracia colombiana, comoquiera que atrasó por más de diez años el cumplimiento de la tarea democratizadora y de actualización de las instituciones constitucionales colombianas. Es una evidencia del sentimiento de desconfianza extrema en el régimen presidencial de gobierno de partido y de la rigidez profunda en la administración de la democracia por los dirigentes regionales y locales de los partidos fuertemente fraccionados.

e. La reforma del 4 de enero de 1981 se refiere exclusivamente a la autorización para crear un nuevo departamento en el territorio del Caquetá y su reunión para fines 
electorales con la intendencia del A mazonas; también se refiere a las reglas de quórum decisorio y de mayorías para la adopción de decisiones en las llamadas asambleas departamentales y en los concejos de las entidades territoriales locales.

f. El acto de reforma de la Constitución adoptado por el acto legislativo No. 1 del 10 de noviembre de 1983 por el cual se establece la regla del incremento anual de la remuneración de los miembros del Congreso de la República ligado al promedio ponderado de los incrementos en la remuneración de los servidores públicos de la $\mathrm{Na}$ ción. Se trata de una fórmula que aún hoy se mantiene vigente con algunas modificaciones menores pero que ha servido para legitimar en parte la acción del congreso frente a los electores que no guardan mucho respeto por su función.

g. Durante el periodo que examinamos en este informe, encontramos la más importante de las reformas a la Carta Política de 1886 por su impacto en el régimen político. Se trata del Acto Legislativo $N^{\circ} 1$ de 1986 conocido como de la elección popular de alcaldes y de la reforma municipal. En esta reforma se incluyó por primera vez la posibilidad de las consultas populares de orden local, desafortunadamente dependientes en alto grado de la ley expedida por el congreso aun para cada caso, lo que las hizo imposibles. ${ }^{36}$

Se tramitó durante el gobierno de Belisario Betancourt y para Restrepo Piedrahita, se trató simplemente de una pequeña fractura en una de las falanges de la mano derecha de la estructura del Estado colombiano.

Hasta la expedición del mencionado acto legislativo, los alcaldes eran designados por los gobernadores y el alcalde de Bogotá por el Presidente de la República, lo que hacía evidente el esquema de ausencia de democracia local y de gobiernos de caciques y jefes regionales de los dos partidos tradicionales que se repartían los cargos de modo casi personal y familiar. Con dichos funcionarios designados directamente por los gobernadores departamentales se garantizaban en épocas de paz pública el dominio de las fracciones regionales de los partidos organizados en directorios y en épocas de enfrentamiento civil armado la configuración de plazas inexpugnables bajo el control de un partido o de una de sus fracciones.

No sobra destacar que apenas hace unos días conmemoramos los cincuenta años del inicio de la vigencia y aplicación de los acuerdos bipartidistas que permitieron la creación del pacto de cierre de la democracia y de bloqueo progresivo en el poder bajo las reglas del mal llamado plebiscito que, en verdad sólo fue la refrendación de las reglas del acuerdo bipartidista para frenar el derramamiento de sangre de la violencia colombiana que llegó a contabilizar cerca de trescientos mil muertos en menos de quince años.

36 En el artículo 6 de la mencionada reforma se advertía que "Previo el cumplimiento de los requisitos y formalidades que la ley señale, y en los casos que esta determine, podrán realizarse consultas populares para decidir sobre asuntos que interesen a los habitantes del respectivo distrito municipal". 
La importancia de la llamada elección popular de alcaldes y de las nuevas reglas de la democracia local, incluidas las imposibles consultas populares de orden municipal, radica en buena parte en la introducción de instituciones de deliberación y representación local acompañadas de nuevos recursos por transferencias fiscales y de regalías por explotación de recursos naturales a los entes territoriales del centro a la periferia. Se trató del mayor esfuerzo hecho por las instituciones políticas colombianas para aclimatar una especie de transformación del régimen político y para incorporar las distintas fuerzas sociales y políticas excluidas del sistema durante la vigencia del Frente Nacional.

Esto generó una especie de nuevo contingente de administradores públicos en el ámbito local y la preparación de nuevos dirigentes interesados en el desarrollo local antes que en la descomposición del orden público y en la violencia de partidos y de fracciones. Empero, en las condiciones del régimen de partidos en Colombia, esta importante reforma democratizadora contribuyó al incremento de las fracciones de estos y al surgimiento de un gran número de partidos familiares y de organizaciones de garaje y a la penetración de los dineros del narcotráfico en la financiación y control de los candidatos.

En ese periodo de nuestra historia se produjo una de las más agresivas campañas de exterminio de un grupo político conocido como la Unión Patriótica, integrado por dirigentes sindicales, agrarios y locales, acusados de pertenecer al Partido Comunista y a las organizaciones de las FARC. La participación de la Unión Patriótica en las elecciones locales significó el surgimiento de grupos de criminales dedicados al exterminio selectivo de sus militantes y simpatizantes y a la realización de matanzas de grupos de familiares o de vecinos de pequeñas poblaciones rurales y urbanas acusados de ser colaboradores de aquellas organizaciones que predicaban la combinación de todas las formas de lucha.

De igual modo, el paramilitarismo, los grupos de narcotraficantes y las guerrillas encontraron espacios de acción irregular para incrementar sus acciones y para querer imponer sus cometidos; se generó una nueva y dolorosa vertiente de descomposiciones criminales de la paz pública y de la seguridad nacional con el crimen de candidatos, la amenaza a sus seguidores, el desplazamiento de poblaciones, el exterminio de familias y de militantes así como la ocupación militar irregular de poblaciones y la expulsión de numerosas familias de campesinos trabajadores y de pequeños y medianos propietarios de la tierra.

El asesinato de Luis Carlos Galán y de otros tres candidatos a la presidencia de la república, del procurador general de la nación, del ministro de justicia y de varios magistrados y jueces, así como el de miles de policías, soldados y agentes de seguridad nacional, son parte del desfile de escenas de dolor, llanto y pesar que tuvo que recorrer la nación y el pueblo colombiano; esta situación además pasa por el increíble y absurdo episodio del asalto al palacio de justicia de la nación y el sacrificio de un centenar de empleados y funcionarios de las altas cortes de Colombia en 1985. 
Obsérvese que pasan más de diez años en la historia de la República de Colombia en los que los narcotraficantes organizados en varios cárteles amenazaron la seguridad nacional y desconocieron de modo agresivo a las instituciones colombianas y extranjeras desde el territorio de nuestro país.

Muchas de esas acciones condujeron al establecimiento de especies de "Paraestados" $\mathrm{y}$ de zonas vedadas a las fuerzas del Estado y en no pocos casos se dio la participación de miembros de las fuerzas militares y de policía en las acciones criminales. A hora, sólo después de muchos años se ha venido a judicializar y a sancionar la verdad de los vínculos entre paramilitares, terratenientes, narcotraficantes, militares y policías dedicados al crimen de los disidentes, a la ocupación y apropiación de tierras y al narcotráfico.

10. YOUNES (62) recuerda que desde 1988 durante el Gobierno de Virgilio Barco que había proclamado la aplicación de un nuevo modelo para el régimen político constitucional colombiano del llamado binomio de partido de gobierno y oposición, comenzó un largo proceso de intentos de reforma constitucional, como fue la idea de convocar un plebiscito para derogar las limitaciones que a la luz del fallo de la Corte Suprema habría impuesto el plebiscito de 1957; esta propuesta fracasó por la oposición del Partido Conservador y en su sustitución se llegó a lo que se llamó el A cuerdo de la Casa de Nariño en una especie de transacción bipartidista con la integración de una Comisión Preparatoria que alcanzó a preparar varios documentos de trabajo resultado de sus sesiones y de varias audiencias públicas en las que ya aparecieron propuestas relacionadas con los derechos fundamentales, la conservación del medio ambiente y la protección de los derechos de los indígenas de una parte y de otra la creación de un régimen de cámara única, la eliminación de los llamados auxilios parlamentarios, la elección popular de gobernadores y el voto obligatorio entre otras y desde luego varias propuestas sobre la rama Judicial.

Lamentablemente, el otro órgano de la Rama Judicial integrado por cooptación bajo las más estrictas reglas de la paridad política decretó la suspensión provisional del llamado acuerdo de la Casa de Nariño como si fuese un acto administrativo de carácter preparatorio sometido al control judicial de esa corporación; se le aplicó la fórmula de la Corte Suprema de Justicia sobre la cláusula pétrea de la reforma de la Constitución únicamente por el Congreso de la República.

Luego y ante semejante nuevo y penoso fracaso judicial en las llamadas altas cortes, el ministro César Gaviria Trujillo en nombre del gobierno somete un proyecto de reforma constitucional al Congreso, que como advertimos también debe arruinar muy a su pesar por la presencia de las fuerzas del narcotráfico que adicionaban una regla no prevista e indeseada en la que se prohibía la extradición de nacionales.

El proyecto del gobierno ya incorporaba notables propuestas de fortalecimiento de las instituciones democráticas, del sistema electoral, la administración de justicia, los mecanismos de reforma constitucional y de la organización territorial. Se preveía la 
creación de la Fiscalía General, del Consejo Superior de la Administración de justicia y la protección especial de los derechos.

11. Hasta aquí el pequeño grupo de reformas introducidas durante el período que podemos denominar preconstitucional, que anuncia la búsqueda de vías alternas y difíciles como la de la convocatoria irregular de la reunión de una A samblea Constitucional, por medio de un decreto de estado de sitio de última hora que autoriza la contabilización de los votos no prevista ni en la Constitución ni en la ley promovida por el movimiento apoyado por el mismo gobierno liberal de Virgilio Barco, dentro de las elecciones ordinarias.

12. En buena parte ese bloqueo progresivo en el poder y las condiciones de atraso institucional, acompañado de la inmensa descomposición del orden político, con el crimen y el asedio de los grupos de delincuentes armados de los narcotraficantes, guerrilleros y paramilitares, explican la salida extraconstitucional de la denominada séptima papeleta y de la convocatoria de la reunión de una institución no autorizada en la Constitución ni por las leyes.

13. Como veremos, ahora es la nueva Corte Suprema de Justicia la que al final avala el camino extra constitucional de la Asamblea, pues dice encontrarse ante el pronunciamiento popular ya contabilizado por la organización electoral y ante la imposibilidad de juzgar ese tipo de pronunciamientos políticos previos a su juicio, que llamó en una de las sentencias el clamor popular.

\section{UN CAMINO PENOSO Y ÁSPERO HACIA UNA SOCIEDAD PLURA LISTA. EL NUEVO ESTADO MULTIORGÁNICO Y EL NUEVO PRESIDENCIALISMO}

1. El camino hacia la construcción colombiana de condiciones institucionales y materiales para consolidar un régimen de gobernabilidad democrática, comenzó a partir del cambio constitucional de 1991, en medio de profundas debilidades sociales, económicas y culturales que han amenazado su legitimidad.

Este recorrido también se ha hecho en un entorno complejo de violencias de diversa etiología, heredadas del periodo preconstitucional, situación que se ha visto agravada por el desarrollo material y humano del ejercito de las FA RC en un sorprendente y masivo desafío armado, y por la virulencia desatada por los llamados grupos de paramilitares que alcanzaron ser a cerca de veinticinco mil hombres armados y movilizados en varias regiones del territorio nacional. Esta situación hoy se mide en miles de muertos, en centenares de masacres y en permanentes acciones que provocan inhumanos desplazamientos de la población rural pobre.

También se han sufrido graves alteraciones del orden público de corte terrorista, en muchos casos generadas por ordenes y acciones de las bandas de delincuentes, sin 
duda dedicadas al narcotráfico y a toda clase de operaciones de bandidaje de izquierda y de derecha como el secuestro, la extorsión, las amenazas y la expropiación ilegal de predios. Ejércitos y bandas de delincuentes nutridos con los recursos y la financiación de la actividad narcotraficante de sus miembros, gravitan en el régimen político colombiano y promueven situaciones de ingobernabilidad.

Esta situación de inestabilidad del orden público policivo y de crisis cíclicas de la seguridad pública en buena parte del territorio rural y de provincia, se han podido enfrentar con propuestas de diálogo, negociación, acuerdos de paz, zonas de distensión, de repliegue, indultos, rebajas de pena, sometimiento a la justicia, reconciliación y de reinserción de excombatientes y con la financiación de grupos especializados de fiscales, jueces, policías, militares e investigadores.

Estos esfuerzos fueros especialmente intensos y costosos durante el gobierno del presidente Andrés Pastrana A rango (1998-2002) y, sin duda crearon una notable percepción mayoritaria de fracaso y de descrédito de las acciones generosas de los gobiernos, como es el caso de la creación de zonas de distensión y diálogo con despejes militares y judiciales como ocurrió en Colombia durante ese periodo.

Se debe advertir inicialmente que con el acompañamiento de la OEA durante el gobierno prolongado por la reelección presidencial de Álvaro Uribe Vélez, autorizada en una reforma constitucional objeto de múltiples críticas de los expertos constitucionalistas y de varios medios de opinión, el Estado se ha empeñado en varias campañas de paz, negociaciones, sometimiento, entrega y sanción con los grupos de paramilitares de las llamadas Autodefensas Unidas de Colombia -AUC-, y que en ese proceso se ha logrado desmovilizar y desarmar a más de 19.000 integrantes de esos grupos; esto se logró bajo un modelo de justicia transicional llamado de Justicia y Paz, y con la llamada Ley de Justicia y Paz, el Gobierno nacional, la Fiscalía General y los jueces pudieron someter a la justicia nacional y a la de los EE.UU. por extradición, a buena parte de sus jefes vinculados por narcotráfico a ambos países.

También es importante destacar en este apartado los "éxitos" de la llamada política de seguridad democrática, la reducción de las estadísticas de secuestros, homicidios, atentados terroristas, acciones de ataque armado a poblaciones y de asalto a carreteras y caminos realizados por las FARC durante los quince años de vigencia de la Carta Política de 1991.

3. A pesar de los profundos esfuerzos de transformación normativa y técnica decretados por la A samblea Nacional Constituyente de 1991 y desarrollados por la acción del poder legislativo y de los jueces en funciones de justicia constitucional por vía de la acción de tutela, las acciones de cumplimiento de la ley y de los actos de la administración y por las acciones populares, la notable agresión armada de los grupos de guerrillas y de paramilitares continúa con fuerza y permitió la adopción de políticas públicas de seguridad policiva y militar, de control a las libertades públicas y de incremento del gasto militar y de policía. 
Todo esto se ha logrado en medio de una relativa estabilidad macroeconómica producto de la tradicional y ahora precaria independencia petrolera, de algunas bonanzas cafeteras y del control financiero y presupuestal que ejerció la llamada junta monetaria; a este respecto cabe observar que la República de Colombia ha recibido más que ningún otro país de la región la fuerte influencia del poder financiero y material del narcotráfico organizado y que éste ha penetrado en varios estamentos la actividad económica con desbordada dinámica y en la vida política en cuyos espacios ha generado condiciones de inestabilidad grave.

4. Parodiando a Restrepo Piedrahita en la primera parte de su informe, creo que el cambio constitucional colombiano que comenzó en 1991 con la expedición de una nueva constitución por una Asamblea Nacional Constitucional que se proclamó constituyente y sin límites, recoge una buena parte de los grandes cambios que viven las sociedades contemporáneas y que se expresan jurídicamente en instituciones poco examinadas entre nosotros, y en las más de 1.200 leyes expedidas en las quince legislaturas que han transcurrido después de la expedición de la Carta Política.

5. Es posible afirmar que a pesar de las graves dificultades de orden público y de seguridad ciudadana que ha sufrido la República de Colombia, el modelo de constitución adoptado en 1991 es visto como un trabajo paradigmático y merecedor de los mayores reconocimientos académicos y políticos; desde luego, el modelo constitucional de justicia y especialmente de administración de justicia constitucional ha desarrollado de modo extraordinario y admirable el texto de la mencionada Constitución Política.

\section{EL CAMBIO CONSTITUCIONAL DESDE LA CARTA POLIITICA DE 1991. LA INSÓLITA OPORTUNIDAD PARA LA DEMOCRACIA Y EL DERECHO CONSTITUCIONAL}

1. El Cambio constitucional colombiano que comenzó en 1991 con la expedición de una nueva Constitución por una A samblea Nacional Constitucional que se autoproclamó constituyente y sin límites, recoge para el sistema político nacional buena parte de las grandes transformaciones y evoluciones que viven las sociedades contemporáneas y que se expresan jurídicamente en instituciones inicialmente poco examinadas entre nosotros, pero desarrolladas inicialmente en las labores de la Comisión Especial Legislativa que creó directamente la misma asamblea y por las quince legislaturas que han transcurrido después de la expedición de la Carta Política. Especialmente cabe destacar las leyes sobre los mecanismos de participación ciudadana, de las reglas para la prestación, control y vigilancia de los servicios públicos domiciliarios, de seguridad social y de medio ambiente que llevan los números 134 y 142 de 1994, 100 y 99 de 1993, respectivamente

2. Como veremos a lo largo de este trabajo, los sistemas jurídicos que se manifiestan en las constituciones contemporáneas como la colombiana de 1991, son en esencia sistemas abiertos integrados principalmente por principios y reglas de carácter 
abierto; además son tendencialmente dinámicos y aparecen compuestos por disposiciones jurídicas que expresan valores superiores, principios generales del ordenamiento jurídico político, principios constitucionales, principios parciales, subprincipios, programas y fines constitucionales; este desarrollo se ha hecho desde luego, con los trabajos de la Corte Constitucional creada bajo el nuevo modelo de justicia y especialmente de administración de justicia constitucional.

Esta Corte y los demás jueces en funciones de tutela de los derechos constitucionales han desarrollado, promovido y ejecutado de modo extraordinario y admirable el texto de la mencionada Constitución Política, de modo especial en materia de los derechos constitucionales fundamentales y de los derechos sociales entre los que ocupan especial lugar los derechos a la seguridad social.

La mencionada actividad jurisprudencial ha sido influenciada de manera notable por la doctrina constitucional europea de la cual se destacan las nociones de la fundamentalización de los derechos sociales, el mínimo vital y de la dignidad de la persona. Es evidente en esta evolución político constitucional que la jurisprudencia de los jueces constitucionales tomó partido por la expansión y desarrollo de los derechos constitucionales.

3. Así, es posible afirmar que a pesar de las graves dificultades de orden público y de seguridad ciudadana que ha sufrido la República de Colombia, el modelo de Constitución adoptado en 1991 se ha aplicado con una dinámica y una fuerza no imaginadas inicialmente y ahora es visto como un trabajo paradigmático y merecedor de los mayores reconocimientos académicos y políticos.

El proceso de legitimación del cambio constitucional en Colombia ha sido arduo y difícil en el plano de las disciplinas jurídicas y, especialmente, en el terreno del derecho judicial y en lo que se ha llamado la disciplina del derecho viviente, principalmente por la fuerte reacción inicial de los representantes del viejo pensamiento jurídico, que encuentran en la vieja judicatura su expresión natural.

La profundidad y dinámica del sentido constitucional de las disposiciones jurídicas introducidas en Carta Política de los colombianos por la A samblea Nacional Constitucional, han significado, además de graves dificultades políticas para el poder legislativo, profundos retos científicos y técnicos para los varios operadores jurídicos, especialmente para los juristas.

No obstante las mencionadas dificultades nacionales, la mayor parte de los juristas y de los operadores jurídicos de la Carta Política de 1991 en nuestro medio, paulatinamente han comprendido que las transformaciones introducidas a partir del texto constitucional, hacen parte de las modernas tendencias del Derecho Constitucional y que, ahora, ellas tienen suficiente espacio de legitimidad en Colombia, como los tienen en la mayor parte de las democracias contemporáneas. 
4. De otra parte pereciera que en la mayor parte de los procesos de reforma a la Carta Política de 1991 se ha tratado de establecer condiciones de gobernabilidad democrática y sostenible para garantizar la viabilidad económica y superar los problemas recurrentes que en países como Colombia se pueden resumir en elementos como la corrupción; la exclusión social y económica; el desempleo; el bajo crecimiento y la inestabilidad económica; impunidad e inseguridad ciudadana.

5. Con base en esta realidad sustancial que se ha consolidado en los últimos quince años de vigencia vigorosa del nuevo texto constitucional, y para comprender sus verdaderas dimensiones y alcances, es necesario el examen sistemático de las transformaciones más recientes de las sociedades y de los Estados contemporáneos y, especialmente, es preciso examinar en varias dimensiones lo que ha ocurrido en Colombia después de la expedición de este documento, especialmente las dificultades y las varias transformaciones políticas, así como los avances y los retrocesos de la disciplina judicial. En todo caso es claro que las nuevas constituciones como la colombiana son el parámetro objetivo de interpretación del resto del ordenamiento constitucional y de la restante estructura del ordenamiento jurídico.

6. La estructura normativa de la Carta Política de 1991 es más rica y compleja que la contenida en la Constitución de 1886, y es reflejo y traducción de las modernas tendencias del derecho constitucional en lo que hace a la adopción de técnicas específicas de redacción de las disposiciones constitucionales sustanciales y a la incorporación más o menos pacífica de contenidos jurídicos relativamente nuevos en nuestro medio, como es el caso de los derechos y de los instrumentos judiciales de protección.

Su valor normativo pleno, decretado directamente por el artículo 40 de la Carta Política, desde el inicio de su vigencia generó serias reflexiones y conflictos técnicos en nuestro medio, pues, como ocurre en las modernas constituciones, su estructura comprende, además de reglas y subreglas específicas de origen, contenido y finalidades políticas, otras disposiciones redactadas en forma de principios, y estos, a su vez, se redactan como objetivos, fines, valores y subprincipios, y principios parciales.

7. De otra parte, los principios y su estructura textual, dada especialmente por la existencia de silencios normativos, generan en muchos casos la posibilidad de reconocer y descubrir la existencia de principios implícitos y de promover por vía legislativa y, ahora por vía judicial, su reconocimiento expreso y práctico.

En este sentido es evidente que esta condición estructural también genera una especie de sobrecarga de principios y que la ausencia de determinaciones normativas objetivas y completas en buena parte de la misma conduce a amplios niveles de indeterminación, flexibilidad y apertura sustancial.

8. Así, aquella Constitución es reflejo y traducción de las modernas tendencias del derecho constitucional en lo que hace, de una parte, a las nuevas formulaciones ideológicas de los modelos de Estado, de sociedad, de derecho y de libertad sustanciales 
que traducen expresiones políticas post-igualitaristas y post-materialistas; dichas tendencias se expresan en la adopción de técnicas nuevas y específicas de redacción y de configuración estructural de las disposiciones constitucionales como aquellas que se refieren a las varias categorías de derechos constitucionales y a las relaciones entre las varias categorías de leyes.

Además, aquellas tendencias se expresan de modo directo en el texto de la Carta Política con la incorporación más o menos pacífica de contenidos jurídicos relativamente nuevos en nuestro medio, como son las pautas y reglas hermenéuticas de origen constitucional que tiene relación con el pluralismo y la democracia, y con la definición e integración multiorgánica del Estado y de las varias administraciones públicas.

9. En cuanto al régimen económico en la Carta Política de 1991 se trata del modelo llamado economía social de mercado y de una nueva modalidad de responsabilidades, compromisos y deberes sociales compartidos entre Estado, administraciones públicas, patronos o empleadores, trabajadores y demás actores de los colectivos sociales abiertos en lo que por otra parte se llama WELL FA RE MIX.

A este respecto cabe señalar que la Constitución Política del Estado español apenas y recién cumplía once años de existencia y su tribunal constitucional no pasaba de más de diez años en funciones; no obstante fue evidente la influencia de sus instituciones complejas en materia de modelo constitucional de la economía y del Estado Social en materias de los derechos y principios de rango constitucional.

\section{LAS MATERIAS DEL CAMBIO Y EL NUEVO MODELO CONSTITUCIONAL EN COLOMBIA}

1. Algunos de los elementos que han transformado el constitucionalismo colombiano contemporáneo son los que integran la noción de Estado social y democrático de derecho para arribar al concepto de Estado democrático avanzado, al reforzar las reglas que permiten alcanzar permanentes y actualizados consensos en los diversos espacios y sedes de la sociedad organizada así como en sus diversos fragmentos, y al reconocer nuevos y diferentes actores sociales válidamente habilitados para desarrollar actividades y para actuar como interlocutores de los cometidos públicos.

En las reformas introducidas a nuestro régimen político constitucional desde la reunión de la A samblea Constituyente se trata de establecer mecanismos institucionales para asegurar a todos los ciudadanos en igualdad de oportunidades el cabal y pleno acceso a una información exacta sobre los programas de acción política y las capacidades e instancias para que se puedan debatir con transparencia y eficacia.

En este sentido se destaca el fortalecimiento de la participación social y la colaboración de los particulares en el ejercicio de las capacidades orientadoras y de planeación, en las responsabilidades del Estado y de la administración, en la prestación de servicios 
y el manejo de bienes, el más amplio espectro de las competencias de los jueces, los nuevos instrumentos de la democracia participativa, la desregulación administrativa y la autorregulación privada, las nuevas libertades económicas, la igualdad sustancial y el acceso a bienes y servicios, son parte de las respuestas del constitucionalismo contemporáneo pluralista y de consenso que se incorporan en la nueva Constitución.

2. De manera muy general y en resumen tenemos que los principales cambios en el régimen constitucional son los siguientes:

a. La forma del Estado pasó de ser la de un Estado Unitario centralizado a la de un Estado Unitario Complejo de configuración progresiva. Se entiende que se pueden crear progresivamente otras entidades territoriales como regiones y provincias, además de los departamentos, municipios y distritos que existen originariamente, al lado de los territorios indígenas que pueden adquirir la categoría de entidades territoriales. A demás, las entidades territoriales se revisten de autonomía administrativa y en parte de autonomía política; también tienen derechos constitucionales y derechos económicos y fiscales respetados como los derechos de los particulares.

b. La noción de soberanía adoptada por la Carta Política de 1991 ahora es la de la Soberanía Popular a diferencia de la vieja noción de soberanía nacional, la que quedó reducida a ser un atributo exterior del Estado colombiano como persona de derecho internacional. Este cambio fundamenta, además, las instituciones de la democracia participativa y deliberativa como el caso de la iniciativa popular, las consultas populares, la revocatoria del mandato, los cabildos abiertos, los varios tipos de referendos entre otros.

c. En materia del régimen político nuestra Constitución adoptó instituciones que equilibran, racionalizan y refuerzan el régimen presidencial tradicionalmente débil, acotado y limitado por los partidos políticos; el Presidente de la República ahora es elegido por mayoría absoluta del 50 por ciento más uno de los votos válidamente depositados y se acude a la segunda vuelta para obtener esta mayoría en caso de ser necesario. Su elección se hace en fórmula conjunta y el mismo día con su compañero a la vicepresidencia.

Se establecen instituciones de desbloqueo y de fortalecimiento del poder presidencial al lado de instituciones de control político como las citaciones a los ministros y la moción de censura, recientemente modificada, dinamizada y extendida a los gobiernos territoriales y locales. Sostenemos que por primera vez se trata de reestablecer la confianza en el gobierno del gobierno y no en el gobierno por estados de excepción.

El presidente colombiano sigue siendo Jefe de Gobierno, Jefe de Estado y Jefe Supremo de la administración; además puede poner en vigencia tratados internacionales de naturaleza económica antes de su adopción legislativa; puede recibir a solicitud suya facultades legislativas temporales y puede decretar con límites normativos, materiales y temporales, los estados de excepción. 
Inicialmente se prohibió la reelección inmediata; posteriormente se introdujo un nuevo régimen en esta materia y en la reforma constitucional de 2004 (Acto Legislativo $\mathrm{N}^{\circ} 2$ de 2004) se introdujo la cláusula que permite la reelección hasta por dos períodos no necesariamente consecutivos.

Luego se reformó el régimen de partidos con listas únicas y con voto preferencial.

d. El régimen económico colombiano fue modificado amplia y profundamente; fue de los apartados constitucionales más transformados, pues se pasó de un régimen intervencionista, asistencial, benefactor, empresario, patrono y empleador, a un Estado de economía social de mercado, dominado principalmente por las ideas y las instituciones del neoliberalismo con componentes solidarios y universalistas en materia de servicios públicos y de seguridad y asistencia social.

Desde la Constitución se propuso la supresión o liquidación de la mayor parte de las empresas estatales, se establecieron las reglas de la desregulación de las actividades privadas salvo la de las actividades bancarias, financieras y aseguradoras, se decretaron fórmulas de apertura e internacionalización de los mercados y de la economía y los derechos a la libre competencia, la libre concurrencia y los derechos de la empresa.

De igual modo, desde la Constitución se ordena la participación de los varios actores privados y sociales en los procesos económicos especialmente en la privatización de las actividades asistenciales y de seguridad social. Como veremos la primera de las reformas introducidas en este campo son las que se refieren a la supresión de la cláusula que permitía la expropiación sin indemnización por razones de equidad que introdujo el gobierno del Presidente Andrés Pastrana al artículo 58 del texto original de la Carta.

e. La organización del Estado Colombiano fue modificada de modo radical como quiera que se pasó del viejo esquema de la división tripartita del poder y de separación orgánica y de colaboración funcional entre los varios actores del régimen político a un Estado multiorgánico con un buen número de órganos, organismo, entes y entidades constitucionales o de importancia y relieve constitucional. Se crearon órganos autónomos e independientes, organismos autónomos de control y órganos y organismos de administración y de gobierno al interior de las ramas del poder.

Como organismos autónomos e independientes tenemos a la Junta Directiva del Banco de la República, la Comisión Nacional de Televisión y la Organización Nacional Electoral.

Como órganos de control, también autónomos e independientes de los poderes ejecutivo, legislativo y judicial aparecen el llamado de modo equívoco en Colombia el M inisterio Público, integrado por la Procuraduría General de la Nación y la Oficina del Defensor del Pueblo; también es órgano de control la Contraloría General de la República, acompañada de las contralorías territoriales y la Auditoría de las contralorías. 
El M inisterio Público colombiano es una institución bien distinta de los ministerios públicos en el derecho comparado y a los que se refiere nuestra disciplina especializada; por lo contrario, la Fiscalía General de la Nación en Colombia es el ministerio público penal, hace parte de la Rama Judicial y por ello funciona con independencia y autonomía política, científica y técnica.

Como organismos de autogobierno y administración al interior de las ramas del poder y aun de los organismos autónomos e independientes tenemos, el Consejo Superior de la Judicatura y la Fiscalía General de la Nación en la Rama Judicial, las direcciones administrativas de las cámaras del Congreso de la República y la Registraduría Nacional del Estado Civil y el Consejo Nacional electoral en la Organización electoral.

Desde luego, esta nueva disposición multiorgánica del Estado colombiano obedece a una concepción contemporánea de neutralización del poder político, especialmente de los miembros de las ramas legislativa y ejecutiva para asegurar mayores niveles de democracia y de neutralidad política en áreas de alta trascendencia para el régimen constitucional.

Como organismos constitucionales tenemos el Consejo Nacional de Planeación, la Comisión de Concertación y de Solución de Conflictos Laborales, la Comisión Nacional del Servicio Civil y la Contaduría General de la República.

f. El régimen de partidos políticos encontró por primera vez en la Carta Política de 1991 una verdadera respuesta democrática y modernizadora con instituciones de variada naturaleza orientadas a su institucionalización, organización y control por los órganos autónomos e independientes de la organización electoral relacionados con su personería jurídica, su organización democrática, con su financiación y con la financiación estatal y con el control de sus gastos.

Se garantizó el derecho a conformar partidos y movimientos sociales y se establecieron las bases del estatuto de la oposición y el acceso a los medios de información. Una de las críticas que se hizo a esta regulación inicial fue su extrema apertura y la facilidad para la constitución de partidos y movimientos políticos y a ello se le atribuyen las causas de algunos problemas del régimen político postconstitucional. Esto motivó varias de las reformas que veremos más adelante relacionadas con las listas, el umbral, la cifra repartidora, el voto preferente y la disciplina de bancadas.

g. En materia de regímenes de control, la Carta Política de 1991 establece un variado y amplio catálogo de instituciones para efectuar el control político del Congreso al poder ejecutivo, el control disciplinario que ejerce de modo preferente el llamado Procurador General de la Nación, el control fiscal y el control penal en los varios fueros que se reconocen.

En algunos casos se han formulado fuertes críticas al funcionamiento de los regímenes de control sobre la conducta de los servidores públicos y se ha llamado a este asunto como penalización de la política y de politización de la justicia penal y disciplinaria. 
Se incorporan como grupos de mecanismos de control civil y de control orgánico los siguientes:

La institución de la acción de tutela sobre la conducta de los servidores públicos cuando amenazan violar o violan los derechos constitucionales fundamentales, las acciones populares relacionadas con la moral administrativa, los bienes y el patrimonio público y los intereses colectivos; el control de legalidad de la jurisdicción de lo contencioso administrativo; los nuevos controles políticos como es el caso de la moción de censura a los ministros y a los altos dignatarios del gobierno y de la rama Judicial. El control fiscal del manejo oficial de los recursos públicos en cabeza de la Contraloría General de la República y el muy efectivo control de constitucionalidad de las leyes y demás disposiciones generales equiparables; también el control de constitucionalidad y de legalidad de los demás actos normativos del Estado en cabeza del Consejo de Estado.

En materia de control fiscal, la Carta Política de 1991 escogió el sistema de la Contraloría General de la República a través del llamado control posterior y selectivo y el control de resultados y de eficiencia de la gestión administrativa y la promoción de las instituciones del llamado control interno de las administraciones.

h. La organización y los supuestos esenciales de funcionamiento de la Rama Judicial y de la Administración de la Justicia resultó tan modificada en esta nueva Constitución que no se conocen precedentes internos relacionados con la mayor parte de sus nuevos principios y reglas. En primer lugar se afirmó un régimen de judicialización de la Constitución y de constitucionalización de la administración de la justicia; se creó la Corte Constitucional que reemplazó a la Corte Suprema en la función del control de constitucionalidad, se creó el Consejo Superior de la judicatura y la Fiscalía General de la Nación.

A demás, se incorporaron instituciones procesales como las de la acción de tutela, las acciones populares y la acción de cumplimento. Se crearon las figuras de los jueces de paz y se reconocieron los derechos de los indígenas para administrar justicia en sus territorios.

i. El régimen de control constitucional fue trasformado sustancialmente no sólo con la creación de la mencionada Corte Constitucional sino con la creación de nuevas vías y procedimientos de control y de acceso a la justicia, especialmente la ya mencionada acción de tutela. En estas materias nuestro régimen ha sido reconocido como uno de los más completos y complejos y la exención de las actividades de la justicia constitucional significan uno de los elementos principales de nuestra evolución. Cabe destacar el enfrentamiento no resuelto entre la Corte Suprema de Justicia y el Consejo de Estado con la Corte Constitucional en materia de la procedencia de las acciones de tutela contra sentencias judiciales. Este enfrentamiento ha generado varios proyectos de reforma constitucional dirigidos a desmontar la acción de tutela de nuestras instituciones, pero, sin excepción, ellos han fracasado de manera rotunda ya que esta insti- 
tución se ha consolidado como una de las de mayor respetabilidad y legitimidad en el nuevo ciclo constitucional.

j. En materias relacionadas con el régimen de los derechos y libertades, encontramos otro grupo de componentes normativos de nuestras instituciones constitucionales que hace parte de las regulaciones sobre los derechos constitucionales.

En estos apartados de la Carta Política de 1991 se aprecian grandes evoluciones de singular importancia, como el catálogo de derechos constitucionales fundamentales cuyo valor ha sido reforzado con las cláusulas de la aplicabilidad inmediata y su refuerzo judicial en las relaciones entre particulares por medio de la acción de tutela que los hace exigibles de modo preferente.

Dicho reforzamiento también aparece con la incorporación del bloque de constitucionalidad y las demás cláusulas preferentes. Además se encuentra un abundante grupo de derechos colectivos y del ambiente, de derechos económicos y de derechos sociales. También existe en la Carta Política de 1991, otro catálogo de derechos económicos y sociales de carácter sustancialmente programático.

Esta cláusula se afirma en la ampliación del catálogo de los derechos constitucionales y en el refuerzo del valor jurídico de los mismos o el establecimiento de una posición preferente de ellos por virtud de la incorporación de los principios que disponen la igualdad material y real de las personas, y la eficacia plena de los derechos constitucionales fundamentales, inclusive en caso de relaciones entre particulares.

2. En el mismo sentido se han impulsado y replanteado algunos elementos de las reformas de las constituciones de la década de los noventa, especialmente en lo que hace a la introducción de reg las de solidaridad, universalidad y generalidad en materia de servicios públicos domiciliarios y de derechos sociales, que plantean la existencia de un modelo de economía social de mercado y que permite altos grados de intervención y orientación pública de los recursos. Esto ha planteado de nuevo y en algunos países nuevas reformas constitucionales que permitan orientar y cautelar las injusticias sociales y el desequilibrio económico.

A demás, la importancia de la Carta Política de Colombia consiste en que desde su redacción inicial, se le introdujeron varios de estos componentes transversales y racionales de solidaridad, generalidad y universalidad, al lado de los elementos relacionados con la productividad, la competitividad, las desregulaciones y la globalización.

3. La realidad económica, política, social y cultural aún dista sustancialmente de las condiciones objetivas requeridas, a tal punto que no se ha logrado siquiera implantar todavía un verdadero Estado de Derecho. Se trata de una sociedad excluyente y fragmentada que no ha logrado cohesionar al conjunto de los ciudadanos en torno de un proyecto colectivo, de un modelo de desarrollo que no ha incorporado productivamente a gran parte de la población en la vida social y económica de la nación, de la 
crisis de lo político como instrumento colectivo de construcción de un orden social a partir de su función de representación y expresión de los interés, problemas y tensiones de la sociedad, y de un Estado ineficaz para el cumplimiento de sus responsabilidades básicas y en ocasiones suplantado por intereses privados poderosos.

\section{LAS MÚLTTPLES REFORMAS A LA CONSTITUCIÓN POLITTICA DE 1991}

1. La Constitución Política de Colombia, en sus primeros diecisiete años de existencia ha recibido varias reformas casi todas aprobadas por el Congreso de la República y sólo una en referendo constitucional, así:

a. El Acto Legislativo 01 de agosto 17 de 1993, se encargó de definir los límites territoriales de la ciudad de Barranquilla como distrito Especial Industrial y Portuario. Este Acto Legislativo modifica el artículo 356 de la Carta Política relacionado nada menos que con el régimen del sistema general de participaciones que son los derechos de las entidades territoriales a recibir los recursos para atender los programas a cargo de las entidades territoriales como los de educación, salud, agua potable y saneamiento básico con base en los principios de solidaridad, complementariedad, subsidiariedad y concurrencia.

El texto de este artículo ha sido modificado en cuatro oportunidades, así: En el acto legislativo 01 de 1993, en el acto legislativo 01 de 2002, en el 02 y en el 04 de 2007. Desde luego, se ha tratado de recomponer una fórmula racional y menos costosa para las finanzas nacionales.

b. El Acto legislativo 02 de 1993 comprendía una serie de disposiciones transitorias previstas para resolver problemas de transición relacionadas con la preparación de los presupuestos anuales y los planes de desarrollo nacional y territorial.

c. En el Acto Legislativo $\mathrm{N}^{\circ} 3$ de 1993, se permitieron de nuevo algunas formas de reemplazo en caso de faltas y temporales de los miembros del Congreso; por medio de esta disposición se revivieron los perniciosos mecanismos de los compromisos locales para sumar votos, lograr la elección de los integrantes de una lista y generar varios carruseles de reemplazos temporales. En muchos casos estos carruseles permiten el acceso a pensiones nutridas y generosas para los reemplazos temporales de los congresistas.

d. En el Acto Legislativo 01 de diciembre 1 de 1995 se adiciona el artículo 357 de la Constitución Política de Colombia y se definen los porcentajes de participación de los municipios en los ingresos corrientes de la Nación y las reglas sobre sus incrementos. Como vemos, esta reforma se encuentra en la misma línea de las introducidas al artículo 356 de la Carta Política y que reseñamos arriba. Se trata del fortalecimiento de la democracia y el desarrollo local. 
e. Por el Acto Legislativo 02 de diciembre 21 de 1995 se adiciona el artículo 221 de la Carta Política para señalar que los tribunales militares y las cortes marciales establecidos para juzgar los delitos cometidos por los miembros de la fuerza pública en servicio activo y en relación con el mismo servicio deben estar integradas por miembros de la fuerza pública en servicio activo o en retiro.

e. Por el Acto Legislativo 01 de enero 15 de 1996 se modifican los artículos 299 y 300 de la Carta y se refiere a la organización y funcionamiento de las asambleas departamentales; la primera de estas disposiciones de la Carta también fue modificada en el acto legislativo 02 de 2002 y el 01 de 2003 y ambas también en el Acto Legislativo 01 de 2007 relacionado con el control político y la moción de censura para los secretarios del poder ejecutivo departamental.

f. Por el Acto Legislativo 01 de diciembre 16 de 1997 se modifica el artículo 35 de la Constitución Política de Colombia y se refiere nada menos que a la posibilidad de solicitar, ofrecer y conceder de conformidad con los tratados internacionales o con la ley en caso de ausencia de aquellos, la extradición de nacionales colombianos por nacimiento por hechos cometidos después de su vigencia; este es uno de los asuntos más complejos del régimen político colombiano. Este cambio constitucional suprime la prohibición establecida en la A samblea Constituyente de 1991 en uno de los episodios más complejos y tortuosos de la historia y de la evolución político constitucional de Colombia. Paradójicamente se tramitó durante el gobierno de Ernesto Samper acusado de recibir dineros de los narcotraficantes del cártel de Cali; Samper no pudo ser juzgado por la Corte Suprema de Justicia, su juez natural, pues la Cámara de Representantes decidió precluir su investigación con fuerza de plena cosa juzgada. Esto significó su plena absolución judicial en la etapa de investigación o de aforamiento penal.

Es decir, en el trámite del procedimiento previo de definición de la procedencia del fuero penal en la Corte Suprema de Justicia, el presidente en ejercicio resultó absuelto por la Cámara de Representantes en uno de los episodios más complejos de la política colombiana durante el período que examinamos.

Lo cierto es que durante este período de notable inestabilidad institucional resultó sacrificado Álvaro Gómez Hurtado varias veces candidato presidencial, hijo del expresidente Laureano Gómez y copresidente de la Asamblea Constitucional. También murieron por atentados terroristas 0 acciones criminales selectivas varios periodistas y varios narcotraficantes involucrados en la actividad política de la época. Se presentó y se aceptó la renuncia del Vicepresidente de la República, se produjo su reemplazo regular y renunciaron varios embajadores; el ministro de la defensa terminó condenado como responsable de recibir los dineros de las mafias de narcotraficantes para las finanzas de la campaña liberal.

g. Por el Acto Legislativo 01 de julio de 1999 se modificó el artículo 58 de la Constitución Política y se suprimió la parte que permitía la llamada expropiación por razones de equidad con el argumento de que era indispensable para incorporar a 
nuestro país en las corrientes de globalización de las economías y de promover la apertura y la integración, asegurar espacios de seguridad jurídica para los inversionistas extranjeros.

La mencionada disposición derogada establecía que "Con todo, el legislador, por razones de equidad, podrá determinar los casos en que no haya lugar al pago de indemnización, mediante el voto favorable de la mayoría absoluta de los miembros de una y otra cámara. Las razones de equidad, así como los motivos de utilidad pública o de interés social, invocados por el legislador, no serán controvertibles judicialmente". Lamentablemente este tema no fue materia de la discusión político constitucional que merecía; lo cierto es que se tramitó de modo pacífico y que no hubo debate digno de nuestra tradición jurídica.

h. Por el Acto Legislativo 01 de agosto 17 de 2000 fue modificado el artículo 322 de la Constitución Política de Colombia, y se cambia el nombre Santa Fe de Bogotá por Bogotá que ya venía organizada como Distrito Capital.

i. Por el Acto Legislativo 02 de agosto 17 de 2000 se modificó el artículo 52 que se refiere a uno de los nuevos derechos sociales de carácter programático y a la posibilidad de regular, inspeccionar e intervenir en las empresas y organizaciones deportivas cuya estructura y propiedad deberán ser democráticas. Se observa la idea de dotar al Estado de herramientas para cautelar y corregir la presencia de dineros del Narcotráfico en esas organizaciones.

j. Por el Acto Legislativo 01 del 30 de julio de 2001, se modifican varios artículos de la Constitución Política, especialmente los relacionados con la prohibición temporal para los años 2002, 2003, 2004, 2005, 2006, 2007 y 2008, de los incrementos las apropiaciones presupuestales para gastos generales dentro del sistema nacional de participaciones y otras transferencias, salvo las destinadas para el pago de pensiones, salud, gastos de defensa, servicios personales. Son previsiones relacionadas con el déficit presupuestal estructural y con la necesidad de recortar o frenar el ritmo de esas transferencias a las entidades que dependen del presupuesto nacional.

k. Con el Acto Legislativo 02 del 27 de diciembre de 2001, se adiciona el artículo 93 de la Constitución que reconoce la jurisdicción penal internacional de la Corte Penal Internacional del Estatuto de Roma.

I. Con el Acto Legislativo 01 del 25 de enero de 2002, se reforma el artículo 96 de la Constitución Política relacionado con las condiciones para adquirir la nacionalidad por nacimiento; con esta disposición se permitió la adquisición de ese tipo de nacionalidad para quienes siendo hijos de padre o madre colombianos, hayan nacidos en el extranjero y sean inscritos en una oficina consular de la República. Con esta nueva regulación se modificó de modo sustancial el régimen de la nacionalidad, en atención a los notables procesos de emigración y de desplazamiento de nacionales en una especie de dispara de la Nación. 
m. Con el Acto Legislativo 02 del 6 de agosto de 2002, se modifican los períodos de los gobernadores, diputados, alcaldes, concejales y ediles para resolver los problemas institucionales de traslape y de confusión de aquellos que la jurisprudencia había señalado como periodos personales; con esta reforma se puso orden en la materia y se concluyó que dichos periodos eran institucionales y debían coincidir en el tiempo.

n. Con el Acto Legislativo 03 del 19 de diciembre de 2002, se modifica sustancialmente la organización judicial de la República, se fortalecen las competencias de la Fiscalía General de la Nación y se impone de modo gradual y progresivo el nuevo régimen penal acusatorio. Se modifican y se refuerzan las competencias del Fiscal General y se establecen los elementos indispensables para su funcionamiento.

o. El Acto Legislativo 01 del 3 de julio de 2003, adoptado dentro del gobierno de Álvaro Uribe Vélez y promovido por su grupo político integrado por representantes de varios partidos, movimientos o fracciones de estos, incorpora numerosas disposiciones relacionadas con la evolución, reestructuración del régimen político colombiano; en éste se adopta una Reforma Política Constitucional y se dictan otras disposiciones, como quiera que se modifican los artículos 107, 108, 109, 111, 112, 125, 135, $160,161,179,258,263,264,266,299$ y 306 de la Carta.

Como vimos, se establecen las reglas sobre pertenencia a los partidos políticos, su organización interna, sus mecanismos democráticos internos y las consultas democráticas para la escogencia de sus candidatos; la inscripción de candidatos, los avales de las directivas de los partidos, el régimen disciplinario interno de los partidos, las bancadas, los asuntos de conciencia para los representantes de los partidos en las corporaciones públicas, el límite del $2 \%$ de los votos como mínimo de los que debe obtener un partido para conservar su personería jurídica. Se regula además, la financiación oficial de los partidos y movimientos políticos con personería jurídica mediante el sistema de reposición de por votos depositados, el acceso a los espacios publicitarios de los candidatos. Se establece de nuevo el régimen de topes máximos a la financiación de las campañas, el estatuto de la oposición de los partidos contrarios al Gobierno como el derecho de acceso a los documentos públicos y su participación en las mesas directivas de las corporaciones públicas.

De igual modo se establecen reglas para el trámite transparente de los proyectos de ley especialmente con las fechas de deliberación, difusión y convocatoria para la votación de los proyectos, el funcionamiento de las comisiones de conciliación y las reglas para la transparencia de sus decisiones, el régimen de inhabilidades para quienes renuncian a un destino en las corporaciones públicas.

Se estableció la regla del valor de los votos en blanco para la elección de los miembros de las corporaciones públicas, gobernadores, alcaldes o para la primera vuelta en la elección presidencial y la posibilidad de la implementación del voto obligatorio. Se incorporó la llamada cifra repartidora, el umbral y se reorganizó de modo tal la integración del Consejo Nacional Electoral y de elección del Registrador del Estado Civil. 
p. Con el Acto Legislativo 02 del 18 de diciembre de 2003, se quiso introducir un estatuto antiterrorista y se modificaron los artículos 15, 24, 28 y 250 supuestamente para dotar el Estado de suficientes herramientas para enfrentar el terrorismo; dicho acto fue declarado inconstitucional por la Corte Constitucional por razones de vicios de forma relacionados con el trámite para su aprobación.

q. Con el Acto Legislativo 01 del 7 de enero de 2004, resultado del primer proceso de referendo reformatorio de la Carta Política se adoptó la pérdida de derechos políticos como sanción adicional para quienes hayan sido condenados en cualquier tiempo por delitos contra el patrimonio del Estado o para quienes con su conducta dolosa o gravemente culposa, hayan dado lugar a condenas contra el Estado; esta reforma fue la única aprobada como resultado del referendo promovido por el gobierno de Álvaro Uribe.

r. Con el Acto Legislativo 02 del 27 de diciembre de 2004, se reforman los incisos 2 y 3 del artículo 127, los artículos 197 y 204 y se adiciona el artículo 152 de la Constitución Política de Colombia para permitir la reelección presidencial inmediata, que supuso un cambio histórico sustancial de nuestro sistema político constitucional.

Como lo advertimos más arriba, es ésta la primera oportunidad en la historia nacional en la que se permite esa modalidad de reelección presidencial, que estuvo prohibida en todas sus modalidades en la versión inicial de la Carta Política de 1991 y por demás, siempre estuvo prohibida durante toda la vigencia de la Constitución de 1886.

s. Con el Acto Legislativo 01 del 22 de julio de 2005, se adiciona el artículo 48 de la Constitución Política en materia del régimen que reconoce los derechos de los pensionados y las reglas de sostenibilidad del sistema pensional. Se reconocen los derechos adquiridos en materia de pensiones. A demás se incorporan reglas novedosas en materia de la sostenibilidad financiera del Sistema General de Pensiones y se establece su carácter centralizado, único y uniforme.

t. Con los actos legislativos 02 del 22 de julio y 03 del 29 de diciembre de 2005, se modifica el artículo 176 de la Constitución Política para definir el régimen de elección de los representantes a la Cámara por la llamada circunscripción de los colombianos residentes en el exterior. Se trata de la organización constitucional de la llamada circunscripción internacional para la elección de un representante a la Cámara, y de la regla que ordena que para ella sólo se pueda sufragar en el exterior por ciudadanos residentes fuera del territorio nacional.

De modo especial, con el Acto Legislativo 03 del 29 de diciembre de 2005, también se modifica el artículo 176 de la Constitución Política, para aumentar para partir del 2010 la base poblacional para la elección de representantes a la Cámara en las circunscripciones territoriales, de una parte, y de otra para establecer las reglas para incrementar dichas bases desde el año 2014. 
Durante esta etapa, es decir en los primeros catorce años de vigencia de la Carta, se produjeron las citadas reformas constitucionales como resultado del trabajo del Congreso de la República; se menciona que también se produjo el intento de reforma introducida por la administración Ernesto Samper Pizano en 1996 que presentó la iniciativa que fracasó de modo lamentable; igual cosa pasó con la presentada por el presidente Andrés Pastrana Arango.

El presidente Álvaro Uribe Vélez presentó la propuesta de reformar la Carta Política de 1991 por la vía del referendo aprobatorio el texto de la ley; esta iniciativa recogía buena parte de sus propuestas de campaña para su mandato; este referendo se cumplió con inmensos costos que llegaron a cerca de ochenta millones de dólares americanos y sólo condujo a la aprobación de la sanción para los condenados por delitos contra el patrimonio del Estado. Las otras propuestas incluidas en el texto de la ley sometida a referendo no recibieron la votación exigida en la Constitución.

A partir de la reforma constitucional que permitió la reelección inmediata de Álvaro Uribe se ha producido un nuevo fenómeno de fortalecimiento de los poderes presidenciales y de desequilibrio de la organización de todos los poderes públicos en el Estado; desde luego este giro se ha dado dentro del marco de una muy vigorosa legitimidad de la acción del gobierno y del presidente; así, es muy probable el trámite de una nueva reelección que ya ha comenzado para que se adopte por la vía del referendo reformatorio de la Carta con iniciativa popular.

La reciente evolución político constitucional de Colombia desde la perspectiva de la Carta Política de 1991, configuró una versión consolidada del presidencialismo equilibrado y moderno que le hacía falta a nuestro régimen político; ahora, con la reelección reeditada, que significa la posibilidad legítima de un tercer período presidencial para Álvaro Uribe Vélez, en nuestro régimen se corre el riesgo de trasladar la mayor parte de los poderes de integración y de orientación de los órganos superiores del poder judicial, de los organismos de control y de los órganos autónomos e independientes, al Presidente de la República. Esto significaría la introducción de una notable tendencia desconocida y repudiada tradicionalmente por el bipartidismo colombiano y el evidente peligro hacia la consolidación de un modelo de presidencialismo hegemónico que no suele traer buenas consecuencias en los regímenes latinoamericanos según experiencias recientes suficientemente conocidas en el medio. De otra parte se advierte de una aproximación a la tendencia de establecer periodos presidenciales largos y de modalidades de elección del jefe del gobierno en varias oportunidades dentro del acuerdo de los partidos en el Congreso.

El Gobierno de Álvaro Uribe Vélez ha mantenido una coalición de partidos gobiernistas que le ha permitido consolidar buena parte de sus políticas y programas, a pesar de que sus más importantes líderes y jefes se encuentran recluidos en prisión por orden de la Corte Suprema de Justicia, investigados o condenados por sus relación con los grupos paramilitares en procura de asegurar sus votos y sus curules en las tres elecciones pasadas, o de obtener otros beneficios ilícitos. 


\section{BIBLIOGRAFÍA}

Acevedo Carmona, Darío (1992), Gerardo Molina, El Magisterio de la Política (Bogotá, Ed. Tercer Mundo).

A нum AdA, Consuelo (1996), El Modelo Neoliberal y su Impacto en la Sociedad Colombiana (Bogotá, Ed. El Áncora Editores).

Alarcón Núñez, Ó scar (2006), "1957-1974 El Frente Nacional”, en Credencial Historia, edición 201, septiembre (Bogotá, Ed. Revista Credencial).

A meRICAS WATCH (1991), La Guerra contra las drogas en Colombia - La olvidada tragedia de la violencia política (Bogotá, Ed. Centro de Estudios Internacionales de la Universidad de los Andes; Instituto de Estudios Políticos y Relaciones Internacionales - IEPRI, Universidad Nacional de Colombia).

Autores Varios (1996), Constitución, Gobernabilidad y Poder (Bogotá, Ed. Universidad Nacional de Colombia, Facultad de Derecho, Ciencias Políticas y Sociales, Universidad Industrial de Santander).

Autores Varios (2008), Para Política Verdades y Mentiras (Bogotá, Ed. Planeta).

A raujo Oñate, Rocío (2007), Balance del Derecho Electoral Colombiano (Bogotá, Editorial Universidad del Rosario).

Barco Vargas, Virgilio, "Del Plebiscito a la Asamblea Constitucional". Informe del Presidente de la República al Congreso Nacional, Tomo VIII, volúmenes I y II.

Bushnell, David (1996), Colombia una Nación a pesar de sí misma, De los tiempos precolombinos a nuestros días (Bogotá, Ed. Planeta Colombiana Editorial).

Cardenas Rivera, Miguel Eduardo, Coordinador (1993), Modernidad y Sociedad Política en Colombia (Bogotá, Ed. Instituto de Estudios Políticos y Relaciones Internacionales - IEPRI, Universidad Nacional de Colombia, Fundación Friedrich Ebert de Colombia, Fescol).

CARPIZo, Jorge (2007), Concepto de democracia y sistema de gobierno en América Latina (Bogotá, Ed. Universidad Nacional Autónoma de México, Instituto de Investigaciones Jurídicas).

CASTRO, Jaime (2008), Constitución Política de Colombia. Concordancias, referencias históricas e índice analítico (Bogotá, Editorial Universidad del Rosario).

Correa Henao, Magdalena (2008), Libertad de Empresa en el Estado Social de Derecho (Bogotá, Editorial Universidad Externado de Colombia).

Dávila Ladrón de Guevara, Andrés (2002), Democracia Pactada, El Frente Nacional y el Proceso Constituyente de 1991 (Bogotá, Ed. Alfaomega Grupo Editor, Universidad de los Andes, CESO Departamento de Ciencia Política).

DeAs, M alcolm (1999), Intercambios Violentos (Bogotá, Ed. Taurus).

De La Calle, Humberto (2004), Contra todas las apuestas. Historia íntima de la Constituyente de 1991 (Bogotá, Editorial Planeta Colombiana).

Dudley, Steven (2008), Armas y urnas, Historia de un genocidio político (Bogotá, Editorial Planeta).

Dugas, John, Compilador (1993), La Constitución de 1991: ¿Un Pacto Político Viable?, (Bogotá, Ed. Universidad de los Andes, Departamento de Ciencia Política, Fescol, Cerec). 
Gandour Pordominsky, Miguel y Mejía Guinand, Luis Bernardo, Compiladores (1999), Hacia el Rediseño del Estado (Bogotá, Ed. Tercer M undo, Departamento Nacional de Planeación).

Garay Salamanca, Luis Jorge, Coordinador General (2002), Talleres del Milenio- Repensar a Colombia - Hacia un Nuevo Contrato Social, PNUD (Bogotá, Ed. Agencia Colombiana de Cooperación Internacional).

Garay Salamanca, Luis Jorge (Dirección A cadémica) (2002), Colombia: Entre la Exclusión y el Desarrollo, Propuestas para la transición al Estado Social de Derecho, (Bogotá, Ed. Contraloría General de la Nación, Carlos Ossa Escobar).

Garay Salam anga, Luis Jorge (Dirección A cadémica) (2008), La Captura y Reconfiguración Cooptada del Estado Colombiano (Bogotá, Ed. Grupo M étodo, Transparencia por Colombia, Fundación AVINA).

Gómez Buendía, Hernando, compilación y análisis (1999), Para dónde va Colombia, (Bogotá, Ed. Tercer Mundo, Colciencias).

Guillerm o prieto, Alma (2008), Las Guerras en Colombia (Bogotá, Ed. Aguilar).

Hartzyn, Jonathan (1993), La Política del Régimen de Coalición, La Experiencia del Frente Nacional en Colombia (Bogotá, Ed. Tercer M undo, Centro de Estudios Internacionales de la Universidad de los Andes).

HARTLYN, Jonathan (1998), "El presidencialismo y la política colombiana”, en Las crisis del presidencialismo, Vol. 2. El caso latinoamericano (Madrid, Ed. Alianza Universidad).

Hernández Galindo, José Gregorio (2005), La Jurisdicción Constitucional sobre el Poder de Reforma de la Constitución en Reforma de la Constitución y Control de Constitucionalidad, Congreso Internacional (Bogotá, Editorial Pontificia Universidad Javeriana, Facultad de Derecho).

HineSTROSA, Fernando (2002), "A dministración de Justicia y Constitución de 1991", en El Debate a la Constitución de 1991 (Bogotá, Ediciones de la Universidad Nacional de Colombia).

Instituto de Estudios Politicos y Rela ciones Internacionales (IEPRI), Universidad Nacional de Colombia (2000), Colombia Cambio de Siglo, Balances y Perspectivas (Bogotá, Ed. Planeta).

Latorre Rueda, Mario (1986), Hechos y critica política (Ed. Universidad Nacional de Colombia).

Leal Buitrago, Francisco y Zamosc, León, Editores (1991), A I Filo del Caos-Crisis Política en la Colombia de los años 80 (Bogotá, Ed. Tercer Mundo, Instituto de Estudios Políticos y Relaciones Internacionales - IEPRI, Universidad Nacional de Colombia). López CABAllero, Juan M anuel (1998), La violencia de los 90s (Bogotá, Ed. Graficas Ducal). López M ICHeLSEN, A Ifonso (2008), ¿Cómo desempantanar el acuerdo Humanitario? (Bogotá, Ed. El Áncora).

López RestRePo, Andrés (2006), "Narcotráfico, ilegalidad y conflicto en Colombia", en Nuestra Guerra sin Nombre (Bogotá, Ed. Grupo Editorial Norma Colección Vitral, Universidad Nacional de Colombia, Instituto de Estudios Políticos y Relaciones Internacionales- IEPRI).

Mayorga García, Fernando (2008), Alfonso López Michelsen, El retrato del intelectual, (Bogotá, Ed. Universidad del Rosario, Facultad de Jurisprudencia). 
Medelín Torres, Pedro (1998), El Retorno a la Política, La Gubernamentalización del Gobierno (Bogotá, Ed. Tercer M undo, PNUD Universidad de los Andes).

MedelLín Torres, Pedro (2006), El Presidente Sitiado, ingobernabilidad y erosión del poder presidencial en Colombia (Bogotá, Ed. Planeta Colombiana).

Mejía Quintana, Óscar (2005), Poder Constituyente, Conflicto y Constitución en Colombia (Bogotá, Ediciones Universidad de los Andes).

NoriegA, Carlos Augusto (1998), Fraude en la elección de Pastrana Borrero (Bogotá, Ed. Oveja Negra).

Olano García, Hernán Alejandro (2007), Constitucionalismo Histórico - La Historia de Colombia a través de sus constituciones y Reformas (Bogotá, Ediciones Doctrina y Ley).

Orjuela Escobar, Luis Javier (2005), La sociedad colombiana en los años noventa: Fragmentación, legitimidad y eficiencia (Bogotá, Ed. Universidad de los Andes, Facultad de Ciencias Sociales-CESO).

Palacios, Marco (2001), De populistas, mandarines y violencias, Luchas por el poder (Bogotá, Ed. Planeta).

Pardo Rueda, Rafael, El Fin del paramilitarismo, ¿Es posible su desmonte? (Bogotá, Ed. Ediciones B Colombia).

Pardo Rueda, Rafael (1996), De primera mano, Colombia 1986-1994: Entre conflictos y esperanzas (Bogotá, Ed. Grupo Editorial Norma).

PARDo Rueda, Rafael (2004), La Historia de las guerras (Bogotá, Ed. Ediciones B Colombia, Javier Vergara Editor).

UnGAR, Elizabeth, Editora (1993), Gobernabilidad en Colombia-Retos y Desafíos (Bogotá, Ed. Departamento de Ciencia Política, Universidad de los Andes).

PeCAUt, Daniel (2008), Las FARC guerrilla sin fin o sin fines (Bogotá, Grupo Editorial Norma).

PeCAUt, Daniel (2006), Crónica de cuatro décadas de política colombiana (Bogotá, Ed. Grupo Editorial Norma, Colección Vitral).

PÉcAut, Daniel (2001), Guerra contra la sociedad (Bogotá, Ed. Planeta, Espasa Hoy).

Peña DaZA, Santiago (1990), Constituyente para profanos (Bogotá, Daza Vanegas Editores).

Peñaranda, Ricardo, GuerRero, Javier (1999), De las armas a la Política, Ed. Tercer M undo (Bogotá, Ed. Centro de Estudios Internacionales de la Universidad de los Andes; Instituto de Estudios Políticos y Relaciones Internacionales - IEPRI, Universidad Nacional de Colombia).

Pérez Escobar, Jacobo (2004), Derecho Constitucional Colombiano (Bogotá, Editorial Temis). Quinche Ramírez, M anuel Fernando (2008), Derecho Constitucional Colombiano (Bogotá, Ediciones Jurídicas Gustavo Ibáñez).

Quinche Ramirez, M anuel Fernando (2004), Reforma Política y Referendo en Colombia: dentro de proceso de reformas a la Constitución de 1991 (Bogotá, Ed. Centro Editorial Universidad del Rosario).

RandalL, Stephen J. (2007), Alfonso López Michelsen, su vida su época (Bogotá, Ed. Villegas Editores).

ReSTREPo Piedrahita, Carlos (1998), "Evolución constitucional en el siglo XX", en Memorias del Congreso Iberoamericano de Derecho Constitucional, Tomo I (Bogotá, Ed. Universidad Externado de Colombia). 
Restrepo Piedrahita, Carlos (1978), Tres Ideas Constitucionales, Supremacía de la Constitución, Corte Constitucional, El Ombudsman (Bogotá, Ed. Universidad Externado de Colombia).

Restrepo Piedrahita, Carlos (1976), 25 Años de Evolución Político-Constitucional 19501975 (Bogotá, Ed. Universidad Externado de Colombia).

Restrepo Piedrahita, Carlos (1973), Las Facultades extraordinarias, Pequeña historia de una transfiguración (Bogotá, Ed. Universidad Externado de Colombia).

Rodríguez Rodríguez, Libardo (2008), Estructura del Poder Público en Colombia (Bogotá, Editorial Temis).

RoLL, David (2001), Un siglo de ambigüedad. Para entender cien años de crisis y reformas políticas en Colombia (Bogotá, Ed. Universidad Nacional de Colombia, Fondo Editorial CEREC-IEPRI).

Roll, David (2001), Rojo difuso Azul pálido, Los Partidos Tradicionales en Colombia entre el Debilitamiento y la Persistencia (Bogotá, Ed. Universidad Nacional de Colombia, Facultad de Derecho y Ciencias Políticas y Sociales).

Roll, David, coordinador (2001), Partidos Políticos y Congreso, Elites políticas y mayorías parlamentarias en Colombia en la década de los noventa (Bogotá, Ed. Universidad Nacional de Colombia, Fundación Konrad Adenauer).

SÁnchez TorRes, Fabio y otros (2007), Las cuentas de la violencia (Bogotá, Grupo Editorial Norma, Colección Vitral, Economía Universidad de los Andes).

Santamaría, Ricardo y Silva Luján, Gabriel (1984), Proceso Político en Colombia, del Frente Nacional a la A pertura Democrática (Bogotá, Ed. Fondo Editorial Cerec).

Tово Rodríguez, Javier (2004), La Corte Constitucional y el Control de Constitucionalidad en Colombia (Bogotá, Ediciones Jurídicas Gustavo Ibáñez).

VALENCIA, León (2007), Los caminos de la A lianza entre los Paramilitares y los Políticos en Para Política La Ruta de la Expansión Paramilitar y los A cuerdos Políticos (Bogotá, Ediciones Corporación Arco Iris, Intermedio Editores).

VÁsquez de UrRutia, Patricia, Compiladora (1989), La Democracia en Blanco y Negro: Colombia en los años ochenta (Bogotá, Ed. Universidad de los Andes, Departamento de Ciencia Política, CEREC).

VILA CASADo, Iván (2007), Fundamentos del Derecho Constitucional Contemporáneo (Bogotá, Editorial Legis).

VILA CASAdo, Iván (2004), Nuevo Derecho Constitucional. Parte General y Colombiana (Bogotá, Ediciones Jurídicas Gustavo Ibáñez).

Younes Moreno, Diego (2007), Derecho Constitucional colombiano (Bogotá, Ediciones Jurídicas Gustavo Ibáñez).

Younes M oreno, Diego (2004), Panorama de las reformas del Estado y de la administración Pública (Bogotá, Centro Editorial Universidad del Rosario).

Waldm Ann, Peter (2007), Guerra Civil, terrorismo y anomia Social, El caso colombiano en un contexto globalizado (Bogotá, Grupo Editorial Norma, Colección Vitral, Fundación Konrad Adenauer). 